OPEN ACCESS

Edited by:

Mark Slevin,

Manchester Metropolitan University,

United Kingdom

Reviewed by:

Yoh Takuwa,

Kanazawa University, Japan

Runping Liu,

Beijing University of Chinese

Medicine, China

*Correspondence:

Liying Li

liliying@ccmu.edu.cn

Specialty section:

This article was submitted to

Inflammation,

a section of the journal

Frontiers in Immunology

Received: 15 February 2020

Accepted: 11 May 2020

Published: 26 June 2020

Citation:

Hou L, Yang L, Chang N, Zhao $X$, Zhou X, Dong C, Liu F, Yang L and Li L

(2020) Macrophage Sphingosine

1-Phosphate Receptor 2 Blockade Attenuates Liver Inflammation and Fibrogenesis Triggered by NLRP3 Inflammasome.

Front. Immunol. 11:1149.

doi: 10.3389/fimmu.2020.01149

\section{Macrophage Sphingosine} 1-Phosphate Receptor 2 Blockade Attenuates Liver Inflammation and Fibrogenesis Triggered by NLRP3 Inflammasome

\author{
Lei Hou ${ }^{1}$, Le Yang ${ }^{1}$, Na Chang ${ }^{1}$, Xinhao Zhao ${ }^{1}$, Xuan Zhou ${ }^{1}$, Chengbin Dong ${ }^{2}$, \\ Fuquan Liu ${ }^{2}$, Lin Yang ${ }^{1}$ and Liying $\mathrm{Li}^{1 *}$
}

${ }^{1}$ Department of Cell Biology, Municipal Laboratory for Liver Protection and Regulation of Regeneration, Capital Medical University, Beijing, China, ${ }^{2}$ Department of Interventional Therapy, Beijing Shijitan Hospital, Capital Medical University, Beijing, China

NLR family pyrin domain containing 3 (NLRP3) inflammasome accompanies chronic liver injury and is a critical mediator of inflammation-driven liver fibrosis. Sphingosine 1-phosphate (S1P)/S1P Receptor (S1PR) signaling participates in liver fibrogenesis by affecting bone marrow (BM)-derived monocytes/macrophage (BMM) activation. However, the relationship between S1P/S1PR signaling and NLRP3 inflammasome in BMMs remains unclear. Here, we found significantly elevated gene expression of NLRP3 inflammasome components (NLRP3, pro-interleukin-1 $\beta$, and pro-interleukin-18) and the activation of NLRP3 inflammasome significantly elevated during murine chronic liver injury induced by a bile duct ligation operation, a methionine-choline-deficient and high-fat diet, or carbon tetrachloride intraperitoneal injection. Moreover, the increased expression of sphingosine kinase 1 (SphK1), the rate-limiting synthetic enzyme of S1P, was positively correlated with NLRP3 inflammasome components in both patients and mouse model livers. Flow cytometry analysis and immunofluorescence staining showed BMMs contributed to the significant proportion of $\mathrm{NLRP}^{+}$cells in murine inflammatory livers, but not Kupffer cells, dendritic cells, endothelial cells, T cells, and hepatocytes. Focusing on macrophages, S1P promoted NLRP3 inflammasome priming and activation in a dose-dependent manner. Blockade of S1PR2 by JTE-013 (antagonist of S1PR 2 ) or S1PR 2 -siRNA inhibited S1P-induced NLRP3 inflammasome priming and inflammatory cytokine (interleukin-1 $\beta$ and interleukin-18) secretion, whereas blockade of $\mathrm{S}_{1 \mathrm{PR}}$ or $\mathrm{S}_{1 \mathrm{PR}}$ had no such effect. in vivo, a $\beta 1,3$-d-glucan-encapsulated siRNA particle (GeRP) delivery system is capable of silencing genes in macrophages specifically. Treatment with S1PR 2 siRNA-GeRPs markedly reduced NLRP3 inflammasome priming and activation and attenuated liver inflammation and fibrosis. Together, the conclusions indicated that targeting macrophage $\mathrm{S}_{1} \mathrm{PR}_{2}$ retarded liver inflammation and fibrogenesis via downregulating NLRP3 inflammasome, which may represent an effective therapeutic strategy for chronic liver injury.

Keywords: macrophage, NLR family pyrin domain-containing 3, inflammation, sphingosine 1-phosphate, S1P receptor 2 , liver injury 


\section{INTRODUCTION}

The inflammasomes are oligomeric complexes formed by innate immune sensors, including NOD-like receptor (NLR) family members NLRP1b, NLRP3, and NLRC4, as well as other nonNLR receptors, such as AIM2 (1). Recent results have shown that the expression of hepatic NLRP3 inflammasome components increases during liver fibrogenesis (2), and NLRP3 expression level is closely correlated with the severity of liver fibrosis (3). Aberrant activation of NLRP3 inflammasome results in severe liver inflammation with immune cell infiltration, hepatic stellate cell activation, and collagen deposition $(4,5)$. Classical activation of the NLRP3 inflammasome requires two independent steps (6). The first step has been referred to as priming, in which activators, such as lipopolysaccharide (LPS), induce nuclear factor- $\mathrm{KB}$ (NF$\kappa \mathrm{B})$ and mitogen-activated protein kinase (MAPK)-dependent expression of NLRP3 inflammasome components, including NLRP3 and pro-interleukin (IL)-1 $\beta$ (6). The second step has been referred to as activation. Upon detection of an activation signal, the adapter molecule ASC links the NLRP3 protein to the recruited caspase-1, resulting in the activation of caspase-1 (6). Active caspase- 1 p10/20 cleaves its target substrates pro-IL- $1 \beta$ and pro-IL-18 into their released mature forms (6).

Sphingosine 1-phosphate (S1P) has emerged as bioactive molecules generated from sphingosine by sphingosine kinase 1 (SphK1) and SphK2 $(7,8)$. It has been reported that S1P can directly act as intracellular signaling molecules or function as the natural ligand of five different types of S1P receptors (S1PRs) (7-9). Recently, S1P/S1PRs signaling has emerged as a crucial regulator of various inflammatoryrelated diseases, such as atherosclerosis, rheumatoid arthritis, and multiple sclerosis, as well as cholestasis-induced liver injury (10). In patient and mouse model injured livers, S1P levels and the expression of SphK1 and S1PRs are markedly upregulated, whereas the mRNA expression of SphK2, S1P phosphatases, and S1P lyase show little changes (11-13). Overactive SphK1/S1P/S1PRs signaling exerts powerful proinflammatory and pro-fibrotic effects, and thus aggravates tissue damage $(11,12,14-20)$. Our previous studies showed that S1P mediates the angiogenic process in hepatic stellate cells required for fibrosis development during liver injury via $S 1 \mathrm{PR}_{1}$ and $\mathrm{S} 1 \mathrm{PR}_{3}$, whereas $\mathrm{S} 1 \mathrm{P} / \mathrm{S} 1 \mathrm{PR}_{2}$ signaling is involved in promoting hepatic stellate cell contraction $(12,21,22)$. S1P/S1PR $2 / 3$ signaling plays a significant role in liver injury by affecting the infiltration and pro-inflammatory M1 polarization of bone marrow-derived monocyte/macrophages (BMMs) (14-16). In addition, the substantial secreted inflammatory cytokines caused by S1P/S1PR

\footnotetext{
Abbreviations: NLR, nod-like receptor; NLRP3, NLR family, pyrin domain containing 3; AIM2, absent in melanoma 2; NLRC4, NLR family, CARD domain containing 4; Nlrp1b, NLR family, pyrin domain containing 1B; ASC, apoptosisassociated speck-like protein containing a CARD; IL, interleukin; BDL, bile duct ligation; MCDHF diet, methionine-choline-deficient and high-fat diet; $\mathrm{OO}$, olive oil; $\mathrm{CCl} 4$, carbon tetrachloride; $\mathrm{BM}$, bone marrow; $\mathrm{BMM}$, bone marrow-derived monocyte/macrophage; S1P, Sphingosine-1-phosphate; S1PR, S1P Receptor; SphK1, sphingosine kinase 1; LPS, Lipopolysaccharide; ATP, adenosine 5'-triphosphate disodium salt; GeRPs, $\beta 1,3$-d-glucan-encapsulated siRNA particles.
}

signaling directly participate in chronic inflammation and tissue damage, such as IL-6 and tumor necrosis factor (TNF)- $\alpha$ $(14-16,19)$. Furthermore, blockade of $\mathrm{S} 1 \mathrm{P} / \mathrm{S} 1 \mathrm{PR}_{2}$ signaling significantly reduces secretion of inflammatory cytokines, enhances regenerative response of hepatocytes, and ameliorates the inflammation and fibrosis during liver injury effectively $(14-18,23,24)$. These effects suggest that targeting S1P/S1PRs signaling will be viewed as a promising strategy for the treatment of liver fibrosis. Owing to S1PRs are widely expressed in various kinds of cells, traditional delivery methods-systemic administration can lead to undesirable systemic side effects (2528). Thus, efficiently delivering pharmacological inhibitors or siRNA into specific cells is expected to be a more effective therapy for the treatment of liver diseases.

Here, we displayed that NLRP3 mainly expressed and functioned in BMMs via an overactive $\mathrm{S} 1 \mathrm{P} / \mathrm{S}_{\mathrm{P}} \mathrm{PR}_{2}$ system, highlighting the key role of macrophage $\mathrm{S}_{\mathrm{PPR}}$ as an effective therapeutic target of NLRP3 inflammasome-dependent sterile inflammation. Previous results have shown that a $\beta$ 1,3-dglucan-encapsulated siRNA particle (GeRPs) delivery system is capable of silencing genes in macrophages specifically (29, 30). In our study, selective knockdown of macrophage $\mathrm{S}_{1} \mathrm{PR}_{2}$ by $\mathrm{S}_{1} \mathrm{PR}_{2}$ siRNA-GeRPs downregulated NLRP3 inflammasome and retarded liver fibrogenesis, which may represent a novel therapeutic strategy for chronic liver injury.

\section{MATERIALS AND METHODS}

\section{Reagents}

Sphingosine 1-phosphate (Cay62570-1, S1P) and D-erythroDihydrosphingosine 1-phosphate (AG-CR1-0005, $\mathrm{H}_{2} \mathrm{~S} 1 \mathrm{P}$ ) were from Biomol (Tebu, France). Lipopolysaccharide (L2630, LPS) was from Sigma-Aldrich (St. Louis, MO). ATP (NLRP3 inflammasome inducer) was from Invitrogen (tlrl-atpl, Grand Island, NY, USA). MCC950 (NLRP3 inflammasome inhibitor) was from MedChemExpress (HY-12815, Monmouth Junction, NJ, USA). W146 (10009109, S1PR 1 antagonist), JTE013(10009458, S1PR 2 antagonist), and CAY-10444(10005033, $\mathrm{S}_{1} \mathrm{PR}_{3}$ antagonist) were from Cayman Chemical (Ann Arbor, MI).

\section{Animal Models}

Male ICR mice, $31.0 \pm 1.0 \mathrm{~g}$, at 6 weeks of age were used in this study. Bile duct ligation (BDL) mice were anesthetized and induced by BDL. Sham-operated mice, used as controls, underwent a laparotomy with exposure, but no ligation of the common bile duct was performed. Mice were anesthetized and sacrificed at 1 or 3 days or at 1 or 2 weeks after BDL ( $n=6$ per group). Methionine-choline-deficient and high-fat (MCDHF) mice and carbon tetrachloride $\left(\mathrm{CCl}_{4}\right)$ mice, in detail, mice were fed either a control diet or an MCDHF diet (A06071309, Research Diet) containing $46 \mathrm{kcal} \%$ fat, $18 \mathrm{kcal} \%$ protein, and 36 $\mathrm{kcal} \%$ carbohydrate. Then mice were anesthetized and sacrificed at 28 days $\left(n=6\right.$ per group). $\mathrm{A} \mathrm{CCl}_{4}(1 \mu \mathrm{L} / \mathrm{g} \mathrm{BW}) /$ olive oil $(\mathrm{OO})$ mixture $(1: 9 \mathrm{v} / \mathrm{v})$ was injected into the abdominal cavity of mice twice per week ( $n=6$ per group). Then mice were anesthetized and sacrificed at 4 weeks. All animal work 
was conformed to the Ethics Committee of Capital Medical University and were in accordance with the approved guidelines (approval AEEI-2014-131).

\section{Human Specimen}

Human fibrotic samples (fibrosis stage: F2: 3, F2/F3: 10, F3/F4: 9, F4: 1) were obtained from livers of 23 patients undergoing liver biopsy (12 men, 11 women; mean age: 58 year; range: $25-79$ year). Fibrosis was caused by chronic $\mathrm{HCV}(n=4)$ or $\mathrm{HBV}(n=8)$ infection, cholestatic $(n=1)$ or alcoholic $(n=3)$ liver cirrhosis, drug-induced liver injury $(n=1)$, cryptogenic cirrhosis $(n=$ $4)$, and autoimmune liver disease $(n=2)$. Normal liver samples were collected from eight patients undergoing hepatic resection for hepatic hemangioma ( 3 men, 5 women; mean age: 45 year; range: $29-59$ year). All subjects gave their informed consent for inclusion before they participated in the study. The study was conducted in accordance with the Declaration of Helsinki, and the protocol was approved by the Ethics Committee of Beijing Shijitan Hospital, Capital Medical University, Beijing, China (Project identification code: 2018EC-1).

\section{Immunofluorescence Staining}

BMMs were fixed by $4 \%$ paraformaldehyde and penetrated by $0.2 \%$ Triton X-100 (Amresco, OH, USA). After being blocked with $2 \%$ BSA (Roche, Switzerland), they were incubated with rabbit anti-ASC polyclonal antibody (AG-25B-0006, 1:400, Adipogen, San Diego, USA). FITC-conjugate affinipure goatanti-rabbit IgG (111-095-144, 1:400, Jackson Immunoresearch, PA, USA) was used as a secondary antibody. Nuclei were stained with DAPI.

The liver specimen was fixed in $4 \%$ paraformaldehyde, and frozen sections of $5 \mu \mathrm{m}$ were used for immunofluorescence. Frozen sections were incubated with rat anti-F4/80 polyclonal antibody (sc-71085, 1:400, Santa Cruz Biotechnology, Santa Cruz, CA) and mouse anti-NLRP3/NALP3 monoclonal antibody (AG-20B-0014, 1:400, Adipogen, San Diego, USA) as the first antibody. Cy5-conjugated goat anti-rat IgG (1:400, 112-175-143) and Cy3-conjugated goat anti-mouse IgG (1:400, 115-165-062) was from Jackson ImmunoResearch Laboratories and used as a secondary antibody. Finally, the sections were stained with DAPI and observed under a confocal microscope (LSM510, Carl Zeiss MicroImaging, Jena, Germany).

\section{Flow Cytometry}

Isolation of mouse liver non-parenchymal cells was as described in this section. Subsequently, antibodies including antiF4/80-APC (17-4801-82), anti-CD11c-APC (17-0114-82), anti-CD3e-APC (17-0031-82), and anti-CD31-APC (170311-82, eBioscience, San Diego, CA) were added to the cell suspension, respectively. After $30 \mathrm{~min}$ of incubation at $4^{\circ} \mathrm{C}$ in the dark, the cells were washed with PBS and incubated with fixation/permeabilization buffer (eBioscience, San Diego, CA). Then, the cells were washed and stained with antiNLRP3/NALP3-750 (IC7578S, R\&D Systems, Eugene, Oregon) for $60 \mathrm{~min}$ at $4^{\circ} \mathrm{C}$ and analyzed with a flow cytometer. FACS was performed on a FACSAria and analyzed with FACSDiva 4.1 (BD Biosciences).

\section{Mouse Primary Liver Macrophage and Hepatocyte Isolation}

Livers were minced with scissors and digested at $37^{\circ} \mathrm{C}$ for $30 \mathrm{~min}$ in TESCA buffer containing collagenase $(1 \mathrm{mg} / \mathrm{mL}$; SigmaAldrich) and DNase I ( $5 \mu \mathrm{g} / \mathrm{ml}$; Sigma-Aldrich). After treatment with RBC Lysis Buffer (Gibco; Grand Island, NY), hepatocytes and macrophages were separated using low-speed centrifugation and $70 \% / 30 \%$ percoll density gradient centrifugation (middle layer), respectively.

\section{Preparation and in vivo Administration of Glucan-Encapsulated siRNA Particles}

Cy3-labeled glucan shells were prepared as previously described (29). To prepare a GeRP, 3 nmol siRNA (Dharmacon) were incubated with $15 \mathrm{nmol}$ Endo-Porter (GT17EPD, EP, Gene Tools) in $30 \mathrm{mM}$ sodium acetate $(\mathrm{pH} 4.8)$ for $30 \mathrm{~min}$ at room temperature in a final volume of $200 \mu \mathrm{l}$. Then, $0.3 \mathrm{mg}$ of Cy3labeled glucan shells were dissolved in $50 \mu \mathrm{l} 30 \mathrm{mM}$ sodium acetate $(\mathrm{pH} 4.8)$ and sonicated to ensure homogeneity of the GeRPs. The siRNA-EP solution was added to GeRPs and then vortexed and incubated for $90 \mathrm{~min}$. Tris/EDTA buffer $(10 \mathrm{mM}$ Tris and $1 \mathrm{mM}$ EDTA, pH 8.0) was added to the particles and incubated for $15 \mathrm{~min}$ at room temperature to adjust the $\mathrm{pH}$ to 7.4. The siRNA-loaded GeRPs were then resuspended in PBS aliquoted into tubes for daily dosing and either flash-frozen in liquid nitrogen or stored at $-80^{\circ} \mathrm{C}$.

Male ICR mice, $31.0 \pm 1.0 \mathrm{~g}$, at 6 weeks of age were anesthetized and induced by bile duct ligation (BDL) or sham operation. The i.p. injection of $\mathrm{S}_{\mathrm{PR}}$ siRNA-GeRPs $(1.5 \mathrm{mg}$ GeRPs/kg of body weight) or Nc siRNA-GeRPs (negative control, $1.5 \mathrm{mg}$ GeRPs/kg of body weight) was performed 1 day after operation, then once a day with the same dose for 12 days. Mice were anesthetized and sacrificed at 2 weeks after BDL or sham operation ( $n=6$ per group). Then, the selective uptake of GeRPs in macrophages $\left(\mathrm{F} 4 / 80^{+}\right)$in BDL-treated livers was measured by confocal microscopy. Approximately 300 macrophages $\left(\mathrm{F} 4 / 80^{+}\right)$ or hepatocytes (large nuclear cells) were measured by the software Image-Pro Plus per simple. The mean value of six randomly selected samples was used as the expressed percentage of $\mathrm{Cy}^{+}$cells in total macrophages or hepatocytes.

\section{Histology Analysis}

Liver tissue sections $(5 \mu \mathrm{m})$ were stained with $\mathrm{H} \& \mathrm{E}$ staining for assessment of inflammation and Sirius Red staining for the extent of collagen deposition. The hepatic inflammatory foci or area of fibrosis was measured by computer-assisted image analysis with Leica Qwin V3 software. The mean value of 15 randomly selected areas per sample was used as the expressed percentage of hepatic inflammatory foci and fibrotic area.

\section{BMM Acquisition}

Male ICR mice, $31.0 \pm 1.0 \mathrm{~g}$, at six weeks of age were anesthetized and sacrificed by cervical dislocation at the time of bone marrow (BM) harvest. BM cells were extracted from the tibias and femurs by flushing with culture medium. Extracted BM cells were cultured for 7 days in the presence of L929-conditioned medium. 
BMMs were serum-starved for $6 \mathrm{~h}$ and then used to perform the following experiments.

\section{RNA Interference (RNAi) in vitro}

siRNA sequences targeting specifically mouse $S 1 \mathrm{PR}_{1}, \mathrm{~S}_{1 \mathrm{PR}}$, and $\mathrm{S}_{1 \mathrm{PR}_{3}}$ were from Invitrogen (Thermo Scientific, PA, USA). Forty to fifty percent of confluent BMMs were prepared. Transient transfection of siRNA (40 nmol/L) was used by employing Lipofectamine RNAi MAX (Invitrogen, Carlsbad, CA) as recommended by the manufacturer. Scramble siRNA was used as a negative control. Cells were used to fulfill further experiments after $48 \mathrm{~h}$.

\section{Western Blot Analysis}

Antibodies were as follows: mouse anti-NLRP3/NALP3 monoclonal antibody (AG-20B-0014, 1:2,000, Adipogen, San Diego, USA); rabbit anti-IL-1 $\beta$ monoclonal antibody (\#12426, 1:2,000, Cell Signaling Technology, Beverly, MA, USA); rabbit anti-IL-18 polyclonal antibody (ab71495, 1:2,000, Abcam, Cambridge, UK); mouse anti-caspase-1 (p20) monoclonal antibody (AG-20B-0042, 1:2,000, Adipogen, San Diego, USA); and the appropriate IRDyeTM 800-conjugated secondary antibody (926-32210, 926-32211, 1:10,000, li-cor). Results were normalized relative to $\beta$-tubulin (HC101-01 1:5,000, Transgen Biotech, China) expression.

\section{Measurement of IL-1 $\beta$ and IL-18 by ELISA}

The concentration of IL-1 $\beta$ and IL-18 was measured by an IL$1 \beta$ ELISA kit (BMS6002, Invitrogen, Carlsbad, CA) and an IL-18 ELISA kit (CSB-E04609m, CUSABIO, Houston, USA) according to the manufacturer's instructions. A standard curve was created, and results were normalized to the protein content of the sample.

\section{qRT-PCR}

Total RNA was extracted from frozen liver specimens or cultured BMMs, with or without treatments, then qRT-PCR was performed. Primer sequences are listed in Table 1.

\section{Statistical Analysis}

Results are expressed as mean \pm SEM. Comparisons between two independent groups were performed using a two-sample $t$-test. Comparisons between multiple groups were performed by one-way or two-way ANOVA with post-hoc Tukey's multiple comparison tests when appropriate. Correlation coefficients were calculated by Pearson test. $p<0.05$ was considered significant. All results were verified in at least three independent experiments.

\section{RESULTS}

\section{Liver Injury of Different Etiologies Was Accompanied by Elevated NLRP3 Inflammasome Priming and Activation}

To examine the role of NLRP3 inflammasome in liver injury of different etiologies, we first detected the changes of NLRP3 inflammasome components (NLRP3, pro-IL-1 $\beta$, and pro-IL18) expression in three mouse models of liver injury induced

TABLE 1 | Primer sequence.

\begin{tabular}{|c|c|c|}
\hline Mouse & & Sequence \\
\hline \multirow[t]{2}{*}{ 18s rRNA } & Sense & GTAACCCGTTGAACCCCATT \\
\hline & Antisense & CCATCCAATCGGTAGTAGCG \\
\hline \multirow{2}{*}{$\begin{array}{l}\text { sphingosine kinase } 1 \\
\text { (Sphk1) }\end{array}$} & Sense & ATGGAACCAGTAGAATGCCCT \\
\hline & Antisense & TCCGTTCGGTGAGTATCAGTTA \\
\hline \multirow{2}{*}{$\begin{array}{l}\text { NLR family, pyrin } \\
\text { domain containing } 3 \\
\text { (Nlrp3) }\end{array}$} & Sense & ATTACCCGCCCGAGAAAGG \\
\hline & Antisense & TCGCAGCAAAGATCCACACAG \\
\hline \multirow[t]{2}{*}{ interleukin 1 beta (II1 $\beta$ ) } & Sense & GCAACTGTTCCTGAACTCAACT \\
\hline & Antisense & ATCTITGGGGTCCGTCAACT \\
\hline \multirow[t]{2}{*}{ interleukin 18 (II18) } & Sense & GACTCTTGCGTCAACTTCAAGG \\
\hline & Antisense & CAGGCTGTCTITGTCAACGA \\
\hline sphingosine-1- & Sense & ACTाTGCGAGTGAGCTG \\
\hline
\end{tabular}

phosphate receptor 1

(S1pr1)

sphingosine-1-

phosphate receptor 2

(S1pr2)

sphingosine-1-

phosphate receptor 3

(S1pr3)

NLR family, CARD

domain containing 4

(NIrc4)

absent in melanoma 2
(Aim2)

Antisense

AGTGAGCCTTCAGTTACAGC

Sense

TTCTGGAGGGTAACACAGTGGT

Antisense

ACACCCTITGTATCAAGTGGCA

Sense

TGGTGTGCGGCTGTCTAGTCAA

Antisense

CACAGCAAGCAGACCTCCAGA

Sense

ATCGTCATCACCGTGTGGAG

Antisense

GCCAGACTCGCCTTCAATCA

Sense

GTCACCAGTTCCTCAGTTGTG

Antisense

CACCTCCATTGTCCCTGTTTAT

NLR family, pyrin

Sense

AGTAATCTGGAGGGGTTGGAC

(NIrp1b)

NLR family, CARD

domain containing 3

(Nirc3)

NLR family, pyrin

domain containing 2

(NIrp2)

NLR family, pyrin

domain containing $4 a$

(NIrp4a)

Antisense

GTTGGCAGCCAGGGTATATCA

Sense

CAGATTGGTAACAAAGGAGCCA

Antisense

CGTTCGGTTTATCTTCAGAGCA

Sense

GAAAGCTGGACAAGACTGAGT

Antisense

GGCAGTGGTCTGTGAGAATा

Sense

GGATGCCCAAAGTTATATCGAGC

NLR family, pyrin

domain containing 5

(NIrp5)

NLR family, pyrin domain containing 6 (NIrp6)

Antisense

Sense

Antisense

Sense

Antisense
CCAGGCCAGCATTAACCTCTT GAAAGCACAATGGGTCCTCCA

CTGACGCCTGTTCCACTTCT CTCGCTTGCTAGTGACTACAC 
TABLE 1 | Continued

\begin{tabular}{|c|c|c|}
\hline Mouse & & Sequence \\
\hline \multirow{2}{*}{$\begin{array}{l}\text { NLR family, pyrin } \\
\text { domain containing 9a } \\
\text { (Nlrp9a) }\end{array}$} & Sense & СTTGCTGCAATATCCAAGGGA \\
\hline & Antisense & GGACAGCGGCATAAATTGAACA \\
\hline \multirow{2}{*}{$\begin{array}{l}\text { NLR family, pyrin } \\
\text { domain containing } 10 \\
\text { (Nlrp10) }\end{array}$} & Sense & TCAAGACGCTGAAGTTCCACT \\
\hline & Antisense & TGCTCCGTACATTGAAATCAGTT \\
\hline \multirow{2}{*}{$\begin{array}{l}\text { NLR family, pyrin } \\
\text { domain containing } 12 \\
\text { (NIrp12) }\end{array}$} & Sense & AAGACCGCAATGCACGATTAG \\
\hline & Antisense & TGGAGCGTTCCCACTCTACA \\
\hline \multirow{2}{*}{$\begin{array}{l}\text { NLR family, pyrin } \\
\text { domain containing } 14 \\
\text { (NIrp14) }\end{array}$} & Sense & TCCACAAACGGTAGTCCTTCA \\
\hline & Antisense & АCTTGTCCCTGTTCAATGGGG \\
\hline \multirow{2}{*}{$\begin{array}{l}\text { NLR family member X1 } \\
\text { (NIrx1) }\end{array}$} & Sense & TAGGGCCTTATCCGTTACCA \\
\hline & Antisense & TAAACCACTCGGTGAGGTTCC \\
\hline \multirow{2}{*}{$\begin{array}{l}\text { NLR family, apoptosis } \\
\text { inhibitory protein } 1 \\
\text { (Naip1) }\end{array}$} & Sense & TGCCCAGTATATCCAAGGCTAT \\
\hline & Antisense & AGACGCTGTCGTTGCAGTAAG \\
\hline \multirow{2}{*}{$\begin{array}{l}\text { NLR family, apoptosis } \\
\text { inhibitory protein } 2 \\
\text { (Naip2) }\end{array}$} & Sense & AGCTTGGTGTCTGTTCTCTGT \\
\hline & Antisense & GCGGAAAGTAGCTTGGTGTAG \\
\hline \multirow{2}{*}{$\begin{array}{l}\text { NLR family, apoptosis } \\
\text { inhibitory protein } 5 \\
\text { (Naip5) }\end{array}$} & Sense & TGCCAAACCTACAAGAGCTGA \\
\hline & Antisense & CAAGCGTTAGACTGGGGATG \\
\hline \multirow{2}{*}{$\begin{array}{l}\text { NLR family, apoptosis } \\
\text { inhibitory protein } 6 \\
\text { (Naip6) }\end{array}$} & Sense & TACAGGGAGTTTACAAGACCCC \\
\hline & Antisense & AGTGGCCTGGAGAGACTCAG \\
\hline Human & & Sequence \\
\hline \multirow{2}{*}{$\begin{array}{l}\text { NLR family, pyrin } \\
\text { domain containing } 3 \\
\text { (NLRP3) }\end{array}$} & Sense & GATCTTCGCTGCGATCAACAG \\
\hline & Antisense & CGTGCATTATCTGAACCCCAC \\
\hline \multirow[t]{2}{*}{ interleukin 1 beta (IL1 $\beta)$} & Sense & TTCGACACATGGGATAACGAGG \\
\hline & Antisense & TIITGCTGTGAGTCCCGGAG \\
\hline \multirow[t]{2}{*}{ interleukin 18 (IL18) } & Sense & TCTTCATTGACCAAGGAAATCGG \\
\hline & Antisense & TCCGGGGTGCATTATCTCTAC \\
\hline \multirow{2}{*}{$\begin{array}{l}\text { sphingosine kinase } 1 \\
\text { (SPHK1) }\end{array}$} & Sense & AGAGTGGGTTCCAAGACACCT \\
\hline & Antisense & GGGTGCAGCAAACATCTCAC \\
\hline
\end{tabular}

by bile duct ligation (BDL), methionine-choline-deficient and high-fat $(\mathrm{MCDHF})$ diet, or carbon tetrachloride $\left(\mathrm{CCl}_{4}\right)$. qRTPCR analysis showed that NLRP3, pro-IL-1 $\beta$, and pro-IL-18 mRNA increased continuously throughout the entire stage of BDL-induced liver injury (Figure 1A). Similar results were obtained in liver samples from mice treated with MCDHF diet and $\mathrm{CCl}_{4}$ (Figure 1A). Second, Western blot analysis revealed a pronounced increase in NLRP3, pro-IL-1 $\beta$, and pro-IL-18 expression in BDL-treated livers (Figure 1B). Third, we detected the dynamic changes of NLRP3 inflammasome activation in BDL-treated livers. The protein level of cleaved caspase-1 p20 rose significantly and got to the topmost level after 2 weeks (Figure 1B). Meanwhile, ELISA assay revealed that IL-1 $\beta$ and IL-18 in serum were significantly increased after 3 days of BDL operation (Figure 1C). These results supported the importance of NLRP3 inflammasome in chronic liver injury.

\section{BMMs Contributed to a Significant Proportion of NLRP3 ${ }^{+}$Cells in Injured \\ Livers}

While previous studies provided evidence that NLRP3 existed and was functionally active in various hepatic non-parenchymal cells $(5,31)$, they did not clarify the main origin of NLRP3 ${ }^{+}$ cells. Thus, we investigated the cell-specific expression patterns of NLRP3 in mouse hepatic non-parenchymal cells. FACS analysis showed that the proportion of $\mathrm{NLRP}^{+}$cells in non-parenchymal cells of BDL-treated livers increased markedly compared with that in sham-operated mouse livers (Figure 2A). In addition, the percentage of $\mathrm{NLRP}^{+}$macrophages $\left(\mathrm{F} 4 / 80^{+}\right)$accounted for 79.5 $\pm 6.3 \%$ of total NLRP3 ${ }^{+}$cells, whereas dendritic cells $\left(\mathrm{CD}_{11} \mathrm{c}^{+}\right.$, $20.9 \pm 4.3 \%)$, endothelial cells $\left(\mathrm{CD} 31^{+}, 3.5 \pm 1.1 \%\right)$ and $\mathrm{T}$ cells $\left(\mathrm{CD} 3 \mathrm{e}^{+}, 2.9 \pm 0.6 \%\right)$ showed much lower NLRP3 expression (Figure 2A).

There are two kinds of macrophages in damaged liver: resident Kupffer cells and recruited BMMs (32). Kupffer cells are a population of macrophages resident within the liver, where they locally proliferate and self-sustain (32). To further clarify the expression of NLRP3 in Kupffer cells and BMMs, we performed an $\mathrm{EGPF}^{+}$bone marrow cell transplantation experiment, followed by BDL-induced liver injury. In previous research, we performed F4/80 staining in the chimera mice with $\mathrm{BDL}$ or $\mathrm{CCl}_{4}$-induced liver injury, and we noted that most of Kupffer cells $\left(\mathrm{F} 4 / 80^{+}\right.$and $\left.\mathrm{EGPF}^{-}\right)$were alive and not replaced by bone marrow monocytes $(33,34)$. Here, almost all of $\mathrm{NLRP}^{+}$macrophages were $\mathrm{BMMs}\left(\mathrm{F} 4 / 80^{+}\right.$and $\left.\mathrm{EGFP}^{+}\right)$ in BDL-injured livers, supporting the important role of BMMs in NLRP3-driven immune responses (Figure 2A). Consistently, immunofluorescence staining showed that significant numbers of NLRP3 ${ }^{+}$cells were also positive for F4/80 and EGFP in BDLtreated livers, whereas NLRP3 was undetectable in hepatocytes (large nuclear cells) in our study (Figure 2B). Altogether, our data identified that BMMs contributed to a significant proportion of NLRP3 ${ }^{+}$cells and might act as an important part in NLRP3 inflammasome priming and activation during BDL-induced liver injury.

\section{Macrophage NLRP3 Inflammasome Priming and Activation Was Induced by S1P in Dose-Dependent Manner}

Previous results showed that the upregulation of SphK1 expression resulted in increased S1P concentration in injured liver $(11,12)$; thus, we speculated whether SphK1/S1P signaling 

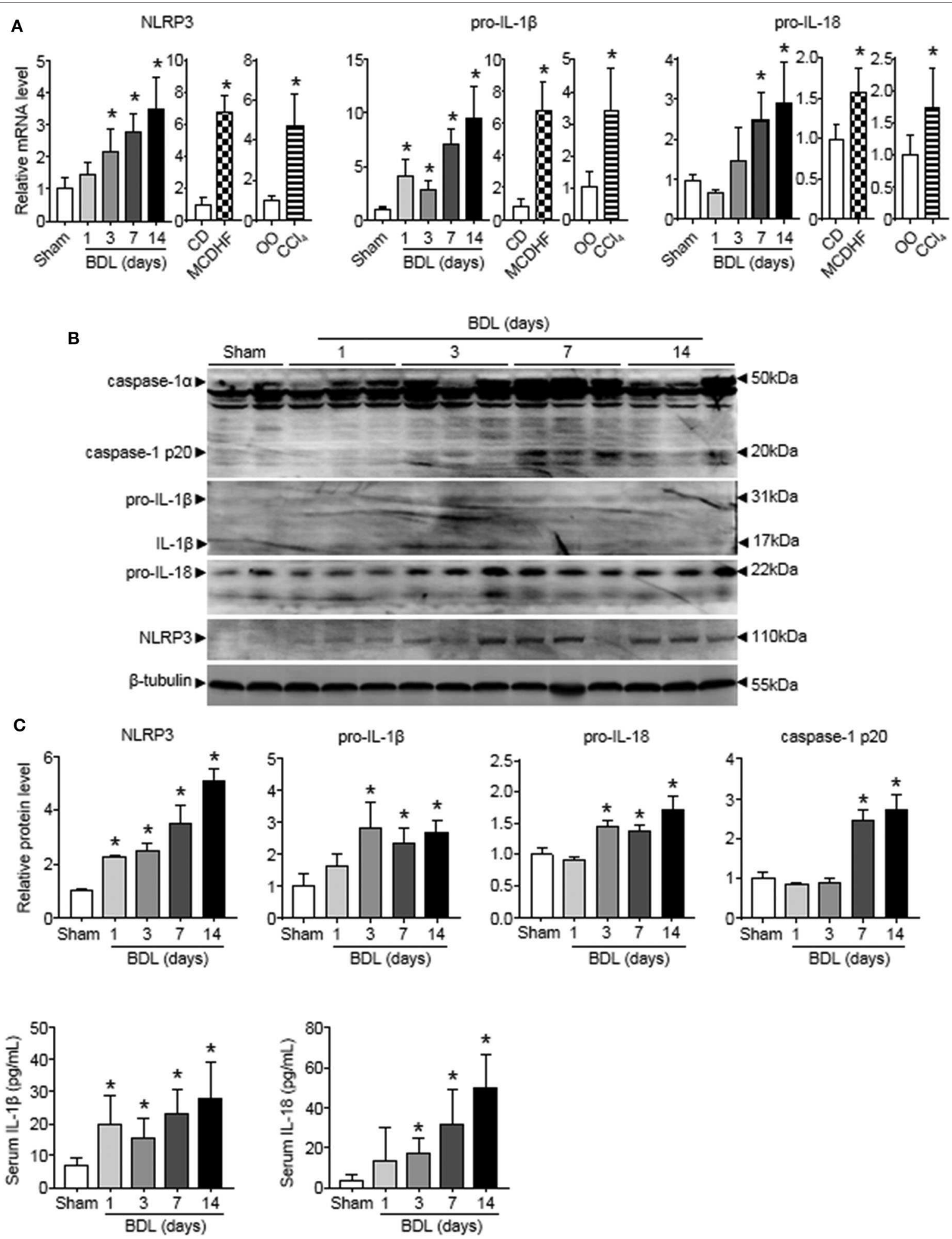

FIGURE 1 | The dynamic changes of NLRP3 inflammasome priming and activation during chronic liver injury. The adult mice received an operation of bile duct ligation $(\mathrm{BDL})$, methionine-choline-deficient and high-fat (MCDHF) diet, or carbon tetrachloride $\left(\mathrm{CCl}_{4}\right)$ treatment to induce liver injury. (A) Expressions of NLRP3, pro-IL-1 $\beta$, and pro-IL-18 in mouse livers were measured by RT-qPCR. (B) NLRP3, pro-IL-1 $\beta$, pro-IL-18, and caspase-1 (cleaved caspase-1 p20 and un-cleaved caspase-1) protein expression from sham-operated and BDL-treated mouse livers were analyzed and quantified by Western blot. (C) ELISA analysis of IL-1 $\beta$ and IL-18 levels in serum. Data are presented as the mean \pm SEM. $n=6$ per group. Comparisons between two independent groups were performed using a student's $t$-test. One-way ANOVA was used for panels (A-C). ${ }^{\star} p<0.05$ vs. control group. 


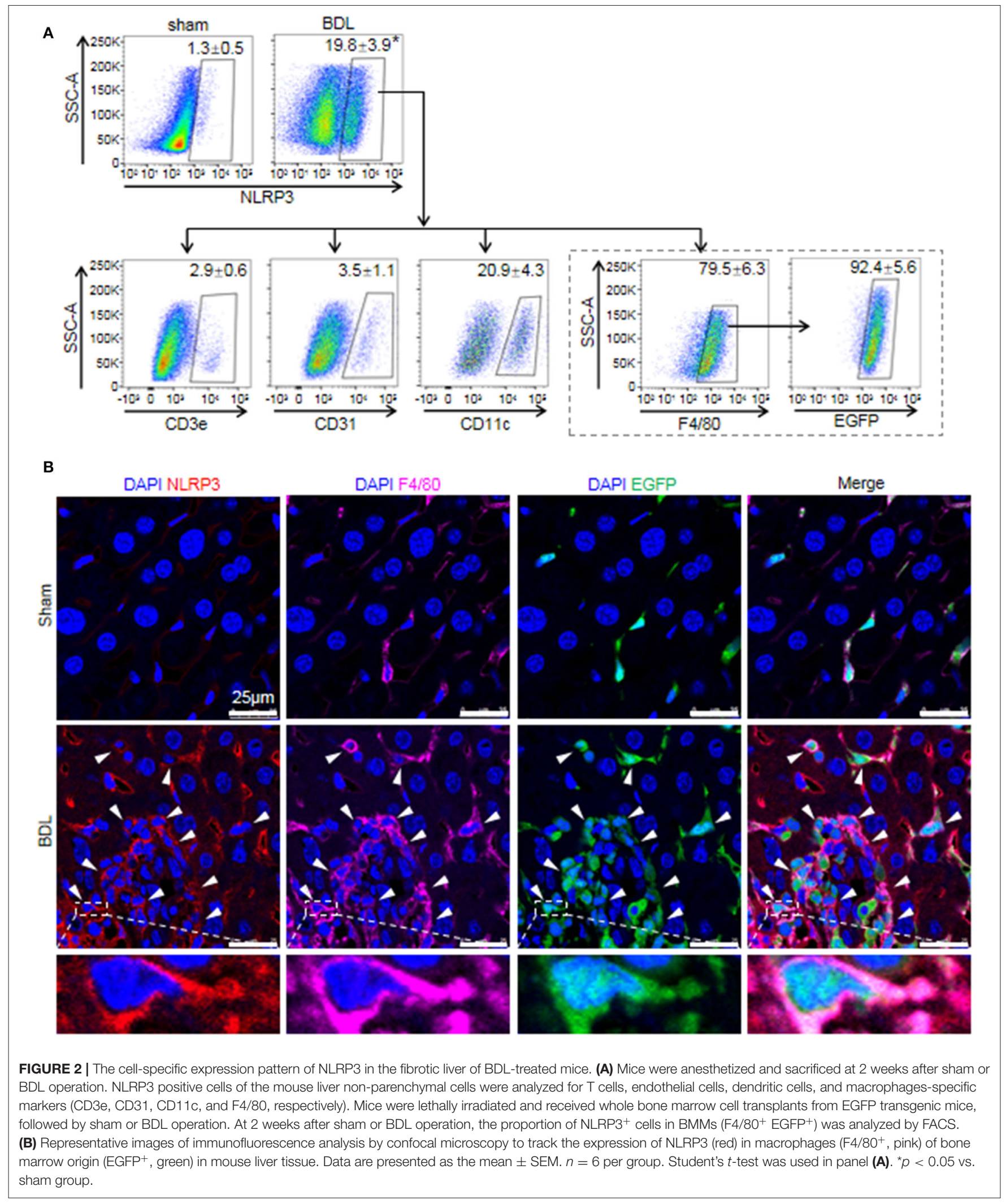

was involved in NLRP3 inflammasome priming and activation. Here, we noted that the mRNA levels of NLRP3 inflammasome components (NLRP3, pro-IL-1 1 , and pro-IL-18) exerted positive correlations with the expression of SphK1, the rate-limiting synthetic enzyme of S1P, in both human and mouse livers (Table 2). Then, serum-starved BMMs were treated with S1P to 
TABLE 2 | The correlation between SphK1 and NLRP3, pro-IL-1 $\beta$, or pro-IL-18 in the liver.

\begin{tabular}{|c|c|c|c|c|c|c|c|}
\hline \multicolumn{2}{|c|}{ Parameter } & \multicolumn{2}{|c|}{ NLRP3 } & \multicolumn{2}{|c|}{ pro-IL-1 $\beta$} & \multicolumn{2}{|c|}{ pro-IL-18 } \\
\hline & Mouse & 0.77 & $<0.05$ & 0.73 & $<0.05$ & 0.63 & $<0.05$ \\
\hline
\end{tabular}

Male ICR mice, $31.0 \pm 1.0 \mathrm{~g}$, at 6 weeks of age received an operation of BDL $(n=24), M C D H F$ diet $(n=6)$, or $\mathrm{CCl}_{4}$ treatment $(n=6)$ to induce liver injury. Sham-operated mice $(n=$ $6)$, OO-treated mice $(n=6)$, and mice fed with control diet $(n=6)$ were used as controls. Human liver samples were obtained from livers of 31 patients with hepatic fibrosis ( $n=23$ ) or hepatic hemangioma $(n=8)$. The mRNA expression of SphK1, NLRP3, pro-IL-1 $\beta$, and pro- $/ L-18$ in human and mouse livers were quantified using qRT-PCR. Then, the relationship between SphK1 and NLRP3, pro-IL-1 $\beta$, and pro-IL-18 was analyzed by regression analysis.

validate the expression of NLRP3 inflammasome components. qRT-PCR and Western blot analysis showed that S1P induced a pronounced increase in NLRP3, pro-IL-1 $\beta$, and pro-IL-18 expression in dose-dependent manner (Figures 3A,B). Bone marrow monocytes differentiated with colony-stimulating factor (M-CSF) are known to prime the macrophage toward the M2 phenotype (35), whereas serum used to culture BMMs contains a large number of nutritional and macromolecular factors essential for cell growth, including S1P (36). Here, we noted that NLRP3, pro-IL-1 $\beta$, and pro-IL-18 mRNA expression in non-serum-starved BMMs was significantly higher than that in serum-starved BMMs (Figure 3A). We also detected the mRNA expression of M1 markers (TNF- $\alpha$ and IL-6) and M2 markers (Arginase-1, CD206, and CD163) in non-serum-starved BMMs, serum-starved BMMs, and serum-starved BMMs treated with S1P. qRT-PCR analysis revealed that Arginase-1, CD163, and IL-6 mRNA expression in non-serum-starved BMMs were significantly higher than that in serum-starved BMMs, while there was no change of CD206 and TNF- $\alpha$ levels in non-serumstarved and serum-starved BMMs (Supplementary Figure 1). Our data supported that L929-conditioned media (M-CSF) induced the M2 phenotype in BMMs. In addition, S1P induced a pronounced increase in the mRNA expression of M1 markers (TNF- $\alpha$ and IL-6) in serum-starved BMMs, whereas S1P had no effects on M2 marker (Arginase-1, CD206, and CD163) mRNA expression (Supplementary Figure 1). These results validated that S1P treatment promoted pro-inflammatory M1 macrophage polarization in BMMs.

Next, we investigated the ability of S1P to stimulate NLRP3 inflammasome activation. Western blot analysis revealed that S1P increased cleaved caspase-1 (caspase-1 p20), mature IL-1 $\beta$, and IL-18 production in dose-dependent manner (Figure 3B). ELISA assay showed that BMMs secreted significant amounts of IL-1 $\beta$ and IL-18 in response to S1P in dose-dependent fashion (Figure 3C). In addition, we found that ASC was evenly distributed throughout unstimulated BMMs. In contrast, NLRP3 was found in small foci that predominantly colocalized with ASC specks in S1P-treated BMMs, which were indicative of NLRP3 inflammasome activation (Figure 4A).

The macrophage can express other intracellular pattern recognition receptors (PRRs), which are also capable of forming inflammasomes, such as NLRP1b, NLRC4, and AIM2 (1). Thus, we examined whether S1P induced IL-1 $\beta$ and IL-18 secretion dependent on NLRP3 inflammasome. Here, we found that
S1P specifically induced NLRP3, AIM2, and NLRC4 mRNA expression, whereas the mRNA fold changes of AIM2 and NLRC4 were much lower than that of NLRP3 (Figure 4B). Then, we pretreated BMMs with MCC950 to further confirm the specificity of S1P-mediated activation of NLRP3 inflammasome (37). Treating BMMs with MCC950 resulted in a strong reduction in the release of mature IL- $1 \beta$ and IL-18 (Figure 4C), indicating that S1P-induced secretion of IL-1 $\beta$ and IL-18 was specifically dependent on NLRP3 inflammasome activation.

\section{S1P Promoted NLRP3 Inflammasome Priming and Increased IL-1 $\beta$ and IL-18 Secretion via S1PR 2 , but Not S1PR 1 and $\mathrm{S}_{1} \mathrm{PR}_{3}$}

To determine whether S1P induced NLRP3 inflammasome priming via S1PRs, we performed the same experiments using $\mathrm{H}_{2} \mathrm{~S} 1 \mathrm{P}$, a structural analog of S1P that is only able to mediate its effects through S1PRs. Here, we found that the effect of S1P on NLRP3, pro-IL-1 $\beta$, and pro-IL-18 mRNA expression was completely mimicked by $\mathrm{H}_{2} \mathrm{~S} 1 \mathrm{P}$ (Figure 5A). Our previous studies have documented that BMMs abundantly express $S 1 \mathrm{PR}_{1}, \mathrm{~S} 1 \mathrm{PR}_{2}$, and $\mathrm{S}_{\mathrm{PR}}$ (14). Next, we determined which S1PR was implicated in this process. For this purpose, the selective S1PRs antagonists were employed. We found that S1P-induced expression of NLRP3, pro-IL-1 $\beta$, and proIL-18 was blocked by JTE-013 (S1PR 2 antagonist) (Figure 5B). Pretreatment with W146 (S1PR 1 antagonist) or CAY-10444 $\left(\mathrm{S}_{\mathrm{PR}}\right.$ antagonist) did not alter $\mathrm{S} 1 \mathrm{P}$-induced the upregulation of NLRP3, pro-IL-1 $\beta$, and pro-IL-18 mRNA level (Figure 5B). Moreover, pretreatment with JTE-013 inhibited S1P-induced mature IL-1 $\beta$ and IL-18 secretion, whereas blockade of $\mathrm{S}_{\mathrm{PR}}$ and $\mathrm{S}_{1} \mathrm{PR}_{3}$ by their selective antagonist had no such effect (Figure 5C).

To further investigate this issue, individual S1PRs were knocked down by specific siRNAs. First, we confirmed that $S 1 \mathrm{PR}_{1}, \mathrm{~S}_{1} \mathrm{PR}_{2}$, or $\mathrm{S}_{\mathrm{P}} \mathrm{PR}_{3}$ siRNA downregulated each mRNA expression in BMMs and that their mRNA expression was reduced by $85 \%, 82 \%$, and $76 \%$, respectively (Figure 6A). Second, silencing $\mathrm{S}_{\mathrm{PR}}$ expression abrogated the increase of NLRP3, pro-IL-1 $\beta$, and pro-IL-18 mRNA expression induced by $\mathrm{S} 1 \mathrm{P}$, whereas siRNA against $\mathrm{S} 1 \mathrm{PR}_{1}$ or $\mathrm{S}_{1} \mathrm{PR}_{3}$ had no effect on that of BMMs (Figure 6B). Furthermore, we noted that the mRNA levels of NLRP3 inflammasome 
A

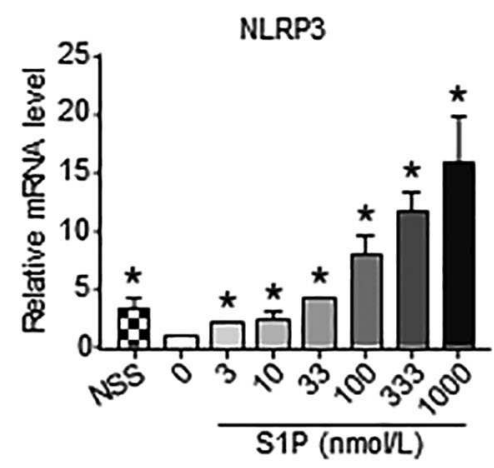

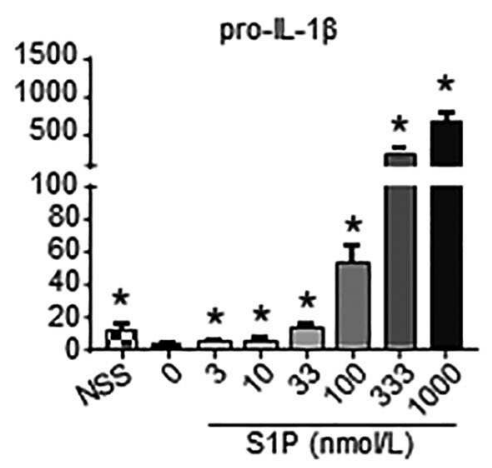

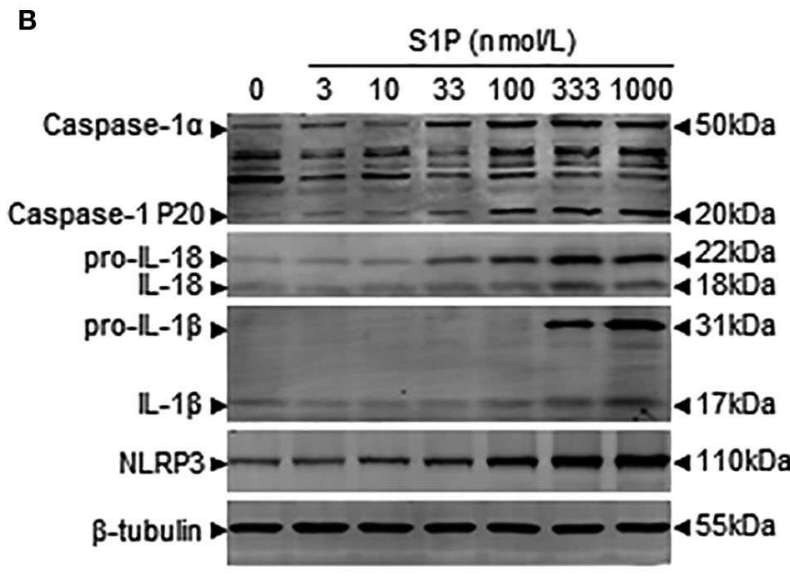

B
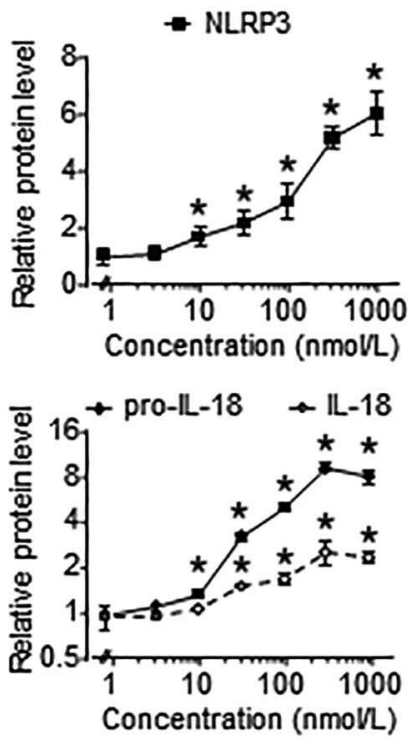

pro-IL-18

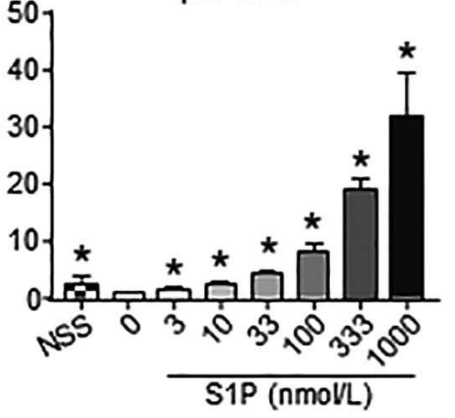

C
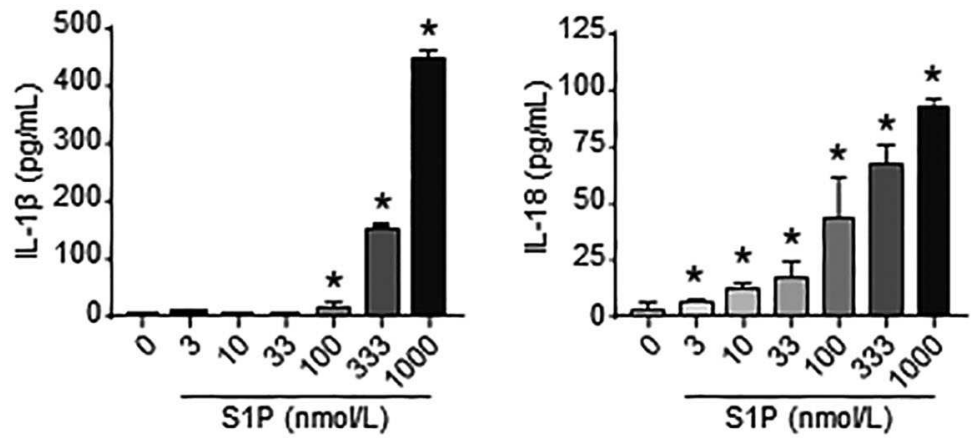

FIGURE 3 | S1P increased NLRP3 inflammasome priming and activation in dose-dependent manner. (A) NLRP3, pro-IL-1 examined by RT-qPCR in non-serum-starved BMMs (NSS), and serum-starved BMMs treated with the indicated concentrations of S1P for $2 \mathrm{~h}$. (B) NLRP3, pro-IL-1 $\beta$, IL-1 $\beta$, pro-IL-18, IL-18, and caspase-1 (cleaved caspase-1 p20 and un-cleaved caspase-1) protein expression were examined and quantified by Western blot in serum-starved BMMs treated with S1P for $12 \mathrm{~h}$. (C) ELISA measurements of IL-1 $\beta$ and IL-18 in culture supernatants from serum-starved BMMs treated with S1P for $12 \mathrm{~h}$. Data are presented as the mean \pm SEM. $n=6$ per group. One-way ANOVA was used for all comparisons. ${ }^{*} p<0.05$ vs. control.

components (NLRP3, pro-IL-1 $\beta$, and pro-IL-18) exerted positive correlations with the expression of $\mathrm{S}_{\mathrm{PR}}$ in mouse livers (Figure 6C). These results supported that macrophage
$S 1 \mathrm{PR}_{2}$ could be an effective therapeutic target for inhibiting NLRP3 inflammasome and alleviating liver inflammation in vivo. 


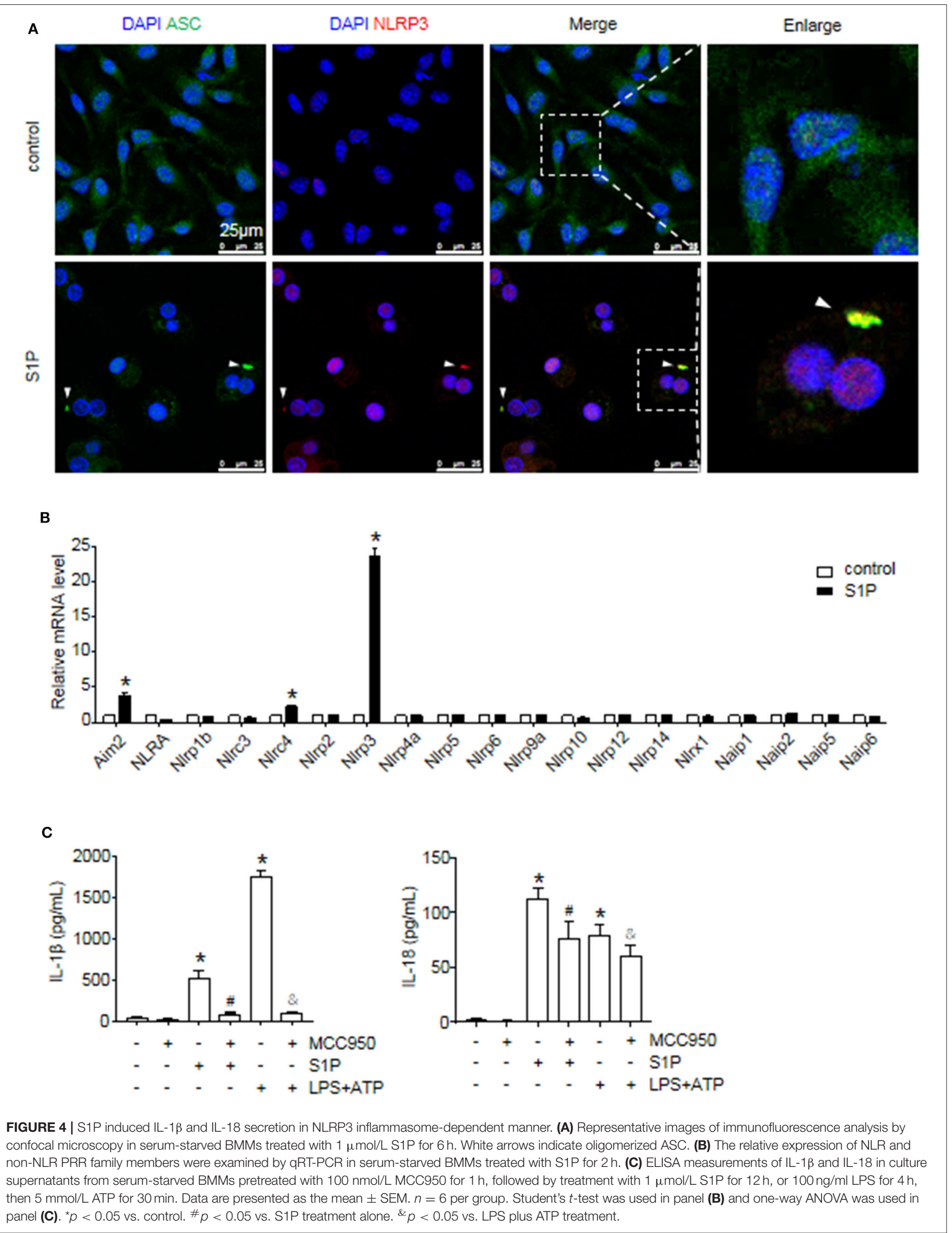



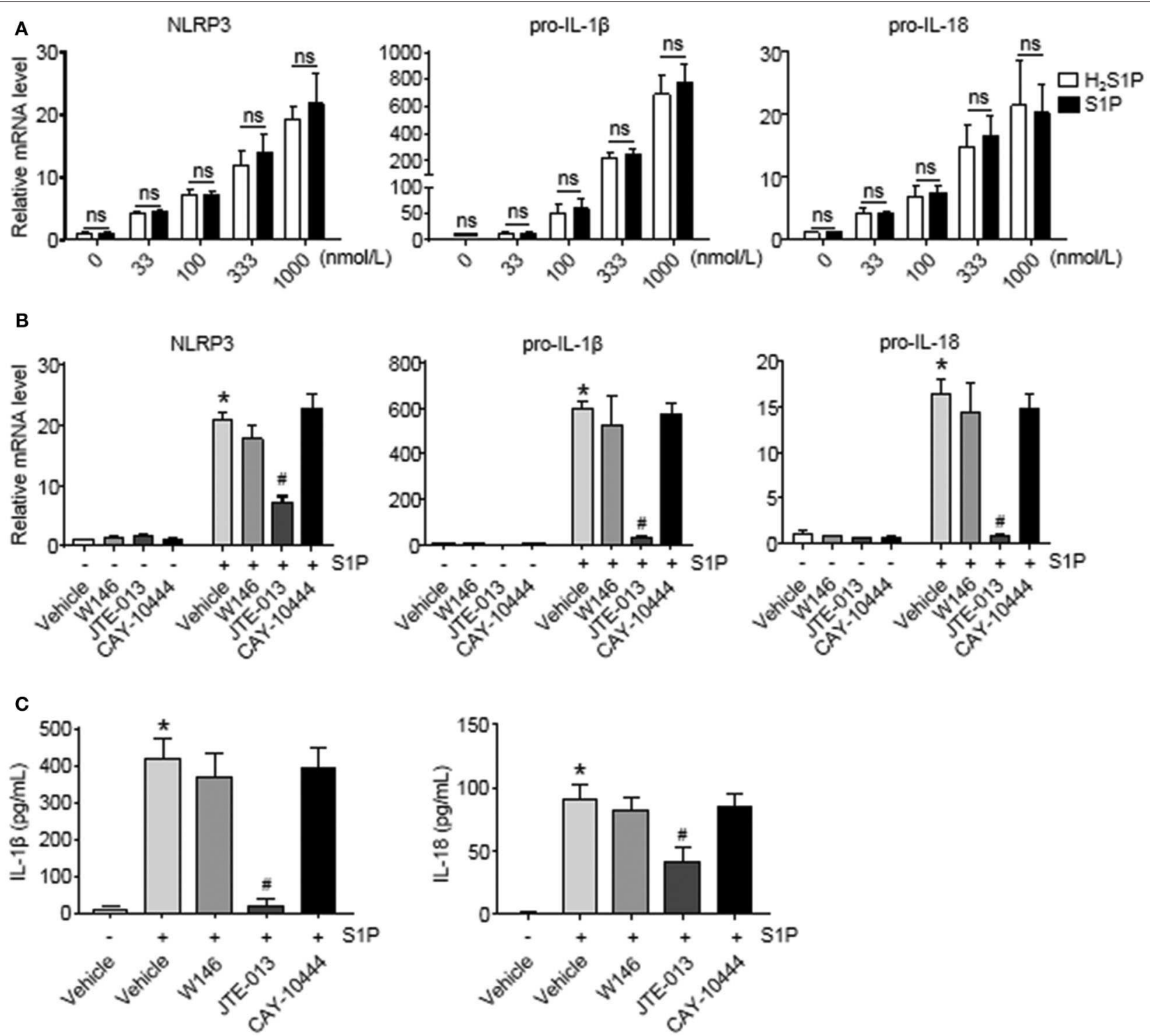

FIGURE 5 | Blockade of S1PR 2 by JTE-013 reduced NLRP3 inflammasome priming and secretion of mature IL-1 $\beta$ and IL-18 in BMMs. (A) The mRNA expression of NLRP3, pro-IL-1 $\beta$, and pro-IL-18 in serum-starved BMMs treated with the indicated concentrations of S1P or $\mathrm{H}_{2} \mathrm{~S} 1 \mathrm{P}$ for $2 \mathrm{~h}$ was examined by qRT-PCR.

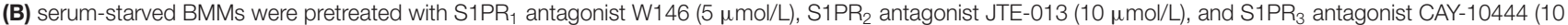

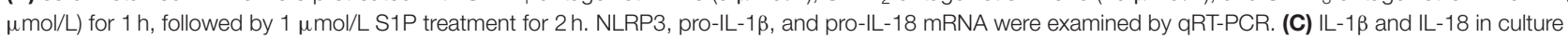
supernatants were examined by ELISA. Data are presented as the mean \pm SEM. $n=6$ per group. Student's $t$-test was used in panel (A) and one-way ANOVA was used in panels (B,C). ${ }^{*} p<0.05$ vs. control, ${ }^{*} p<0.05$ vs. S1P treatment alone, ns, not significant.

\section{S1PR 2 siRNA-GeRPs Were Able to Induce Macrophage-Specific Knockdown of $\mathrm{S1PR}_{2}$ and Downregulate NLRP3 Inflammasome in Mouse Fibrotic Livers}

Previous studies have shown that $\beta$ 1,3-d-glucan-encapsulated the siRNA particle (GeRP) delivery system targets selectivity to macrophages on the basis of their ability to tightly bind and phagocytose such particles $(29,30)$. To track the formation of GeRPs, glucan shells were labeled with Cy3. GeRPs were made as described $(29,30)$, and we also studied GeRPs formation by microscopy (Figure 7A). Immunofluorescence staining showed that Cy3-labeled GeRPs, 2-4 $\mu \mathrm{m}$ in diameter, formed at $\mathrm{pH} 7.4$ could be readily detected (Figure 7A).

Then, we injected ICR mice intraperitoneally daily with $\mathrm{S}_{1} \mathrm{PR}_{2}$ siRNA-GeRPs for 12 days to induce macrophage-specific knockdown of $\mathrm{S}_{\mathrm{PR}}$. Controls received GeRPs containing scrambled siRNA. First, we analyzed the selective uptake for GeRPs in BDL-treated livers. The mean value of 15 randomly selected areas was used to calculate the proportion of macrophages $\left(\mathrm{F} 4 / 80^{+}\right)$and hepatocytes (large nuclear cells) in Cy3-labeled GeRPs positive cells. Consistent with previous 
A $\square$ NC SiRNA

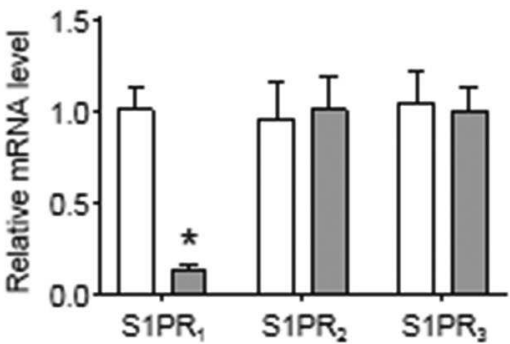

B
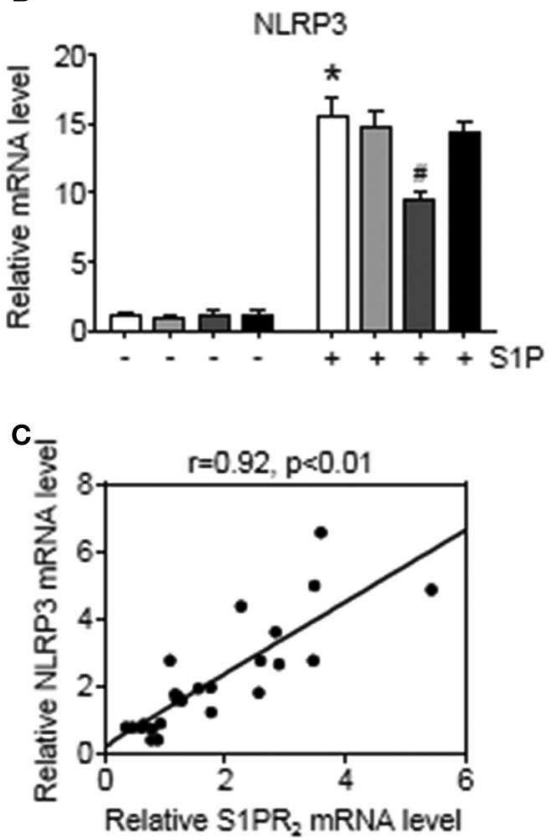

S1PR, SIRNA

S1PR 2 SIRNA

$\mathrm{S}_{\mathrm{PR}}$ SIRNA
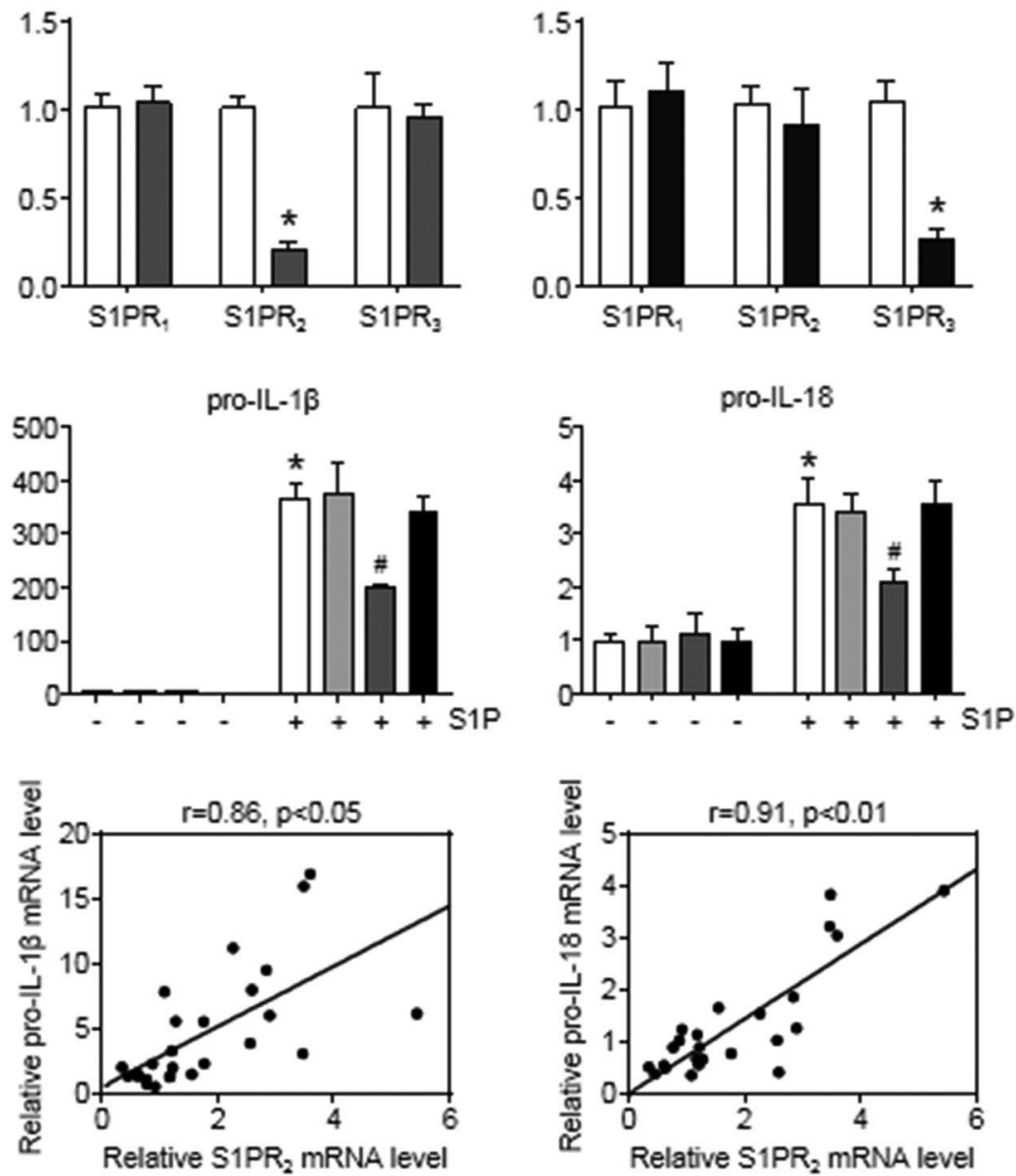

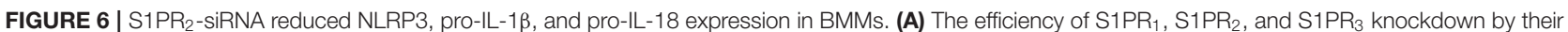
siRNAs in serum-starved BMMs. (B) Effects of S1PR, S1PR 2 , and S1PR 3 siRNA on NLRP3, pro-IL-1 $\beta$, and pro-IL-18 mRNA expression in response to $1 \mu \mathrm{mol} / \mathrm{L}$ $\mathrm{S} 1 \mathrm{P}$ for $2 \mathrm{~h}$. (C) Mice received an operation of BDL to induce liver injury, then were anesthetized and sacrificed at 1 or 3 days or at 1 or 2 weeks after BDL operation. The relationship between S1PR 2 and NLRP3, pro-IL-1 1 , and pro-IL-18 in mouse liver was analyzed by regression analysis. Data are presented as the mean \pm SEM. Student's $t$-test was used in panel (A) and one-way ANOVA was used in panel (B). $n=6$ per group. ${ }^{*} p<0.05$ vs. control; $\# p<0.05$ vs. S1P treatment alone.

reports $(29,30)$, GeRPs were significantly enriched in $\mathrm{F} 4 / 80^{+}$ macrophages, whereas GeRPs were undetectable in hepatocytes (Figures 7B,C). Besides, most of the macrophages $(61.7 \pm 5.9 \%)$ were able to effectively internalize GeRPs (Figure 7D). S1PR siRNA-GeRPs treatment resulted in a significant decline of $\mathrm{S}_{1} \mathrm{PR}_{2}$ mRNA expression in the macrophages of BDL-injured livers, while there was no change of $\mathrm{S}_{1} \mathrm{PR}_{2}$ mRNA levels in hepatocytes (Figure 7E). Second, we analyzed whether targeting macrophage $\mathrm{S}_{\mathrm{PR}} \mathrm{R}_{2}$ may influence NLRP3 inflammasome priming and activation in cholestatic liver injury. Selective knockdown of macrophage $\mathrm{S}_{1 P R_{2}}$ by $\mathrm{S}_{1} \mathrm{PR}_{2}$ siRNA-GeRPs treatment significantly inhibited the expression of NLRP3, pro-IL-1 $\beta$, and pro-IL-18 in BDL-injured livers compared with scrambled siRNA-GeRPs treatment (Figure 7F). Besides, the secretion of IL-1 $\beta$ and IL-18 were markedly suppressed in mice treated with
S1PR 2 siRNA-GeRPs (Figure 7G). Together, our data supported the notion that targeting macrophage $\mathrm{S}_{\mathrm{PR}} \mathrm{PR}_{2}$ attenuated NLRP3 inflammasome-driven inflammation in cholestatic liver injury.

\section{Selective Knockdown of Macrophage S1PR $_{2}$ Attenuated Liver Inflammation and Fibrosis in BDL-Injured Livers}

In the end, we analyzed whether blockade of macrophage $\mathrm{S}_{1} \mathrm{PR}_{2}$ signaling may have retarded liver inflammation and fibrogenesis in cholestatic liver injury. First, the inflammation and fibrotic areas were decreased significantly in the injured livers of mice treated with $\mathrm{S}_{\mathrm{PR}}$ siRNA-GeRPs (Figure 8A). Second, BDL mice treated with $\mathrm{S}_{2} \mathrm{PR}_{2}$ siRNA-GeRPs presented a significant drop in the mRNA expression of fibrosis markers, 
A

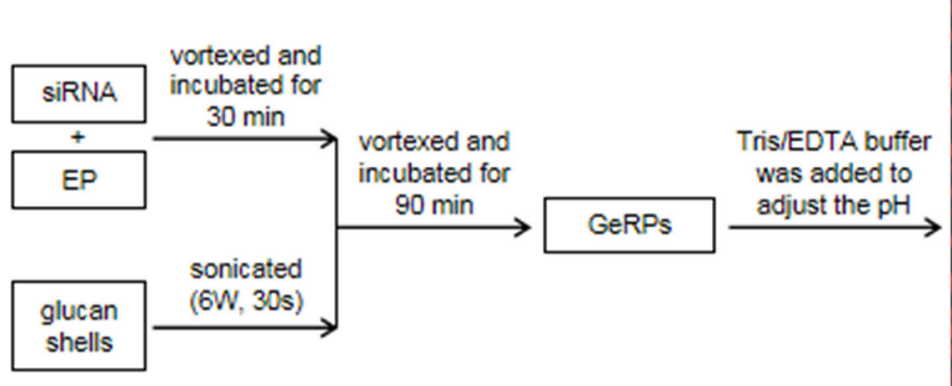

GeRPs

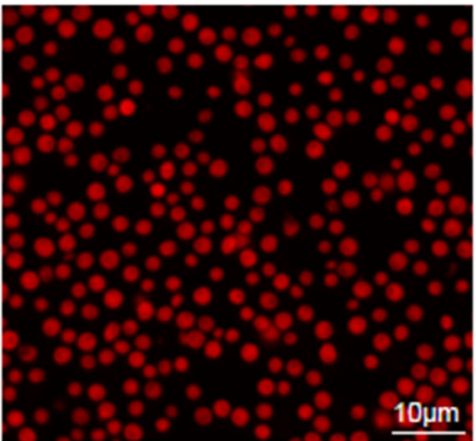

B

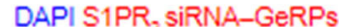

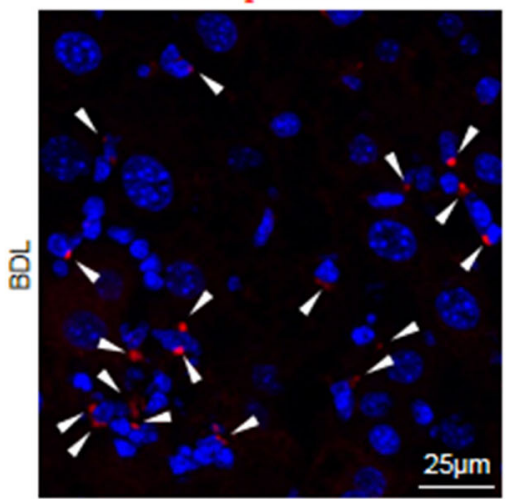

C

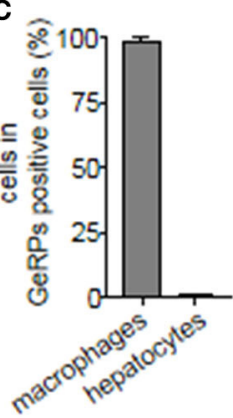

D

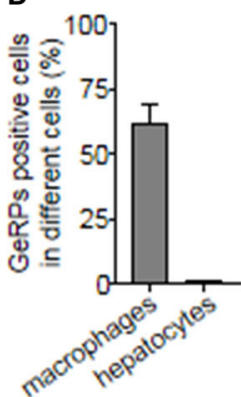

DAPI F $4 / 80$

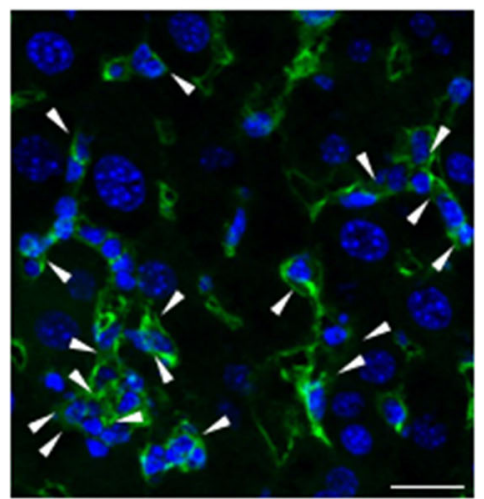

E

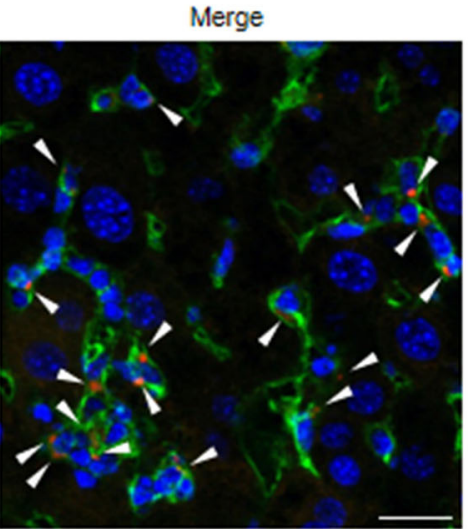

$\mathrm{S} 1 \mathrm{PR}_{2}$

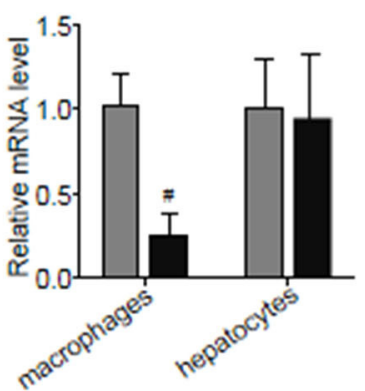

Nc SiRNA + BDL

S1PR 2 SIRNA + BDL

$\square$ Nc siRNA + sham

$\mathbf{F}$

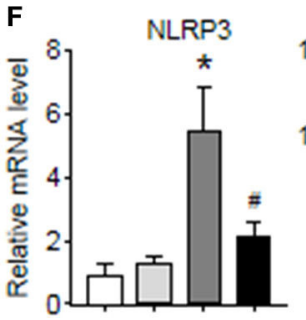

$\square S 1 P R_{2}$ siRNA + sham

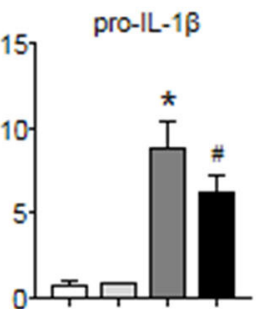

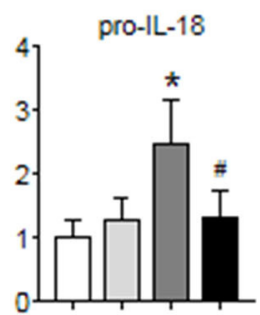

Nc SiRNA + BDL

ص $\mathrm{S} 1 \mathrm{PR} \mathrm{R}_{2}$ SIRNA + BDL

G
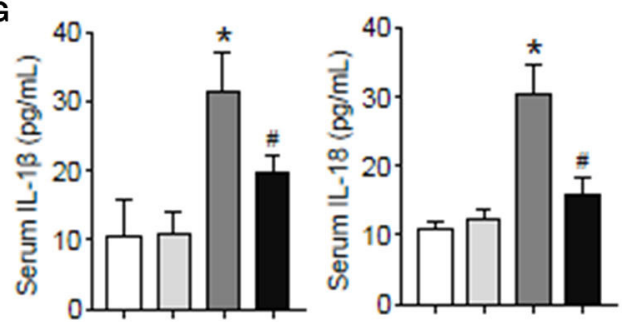

FIGURE 7 | S1PR 2 siRNA-GeRPs was able to induce macrophage-specific knockdown of S1PR 2 and downregulate NLRP3 inflammasome in BDL-injured livers, (A) Strategy for loading Cy3-labeled glucan shells with siRNA-EP complexes and representative images of GeRPs (red). (B-D) Representative images and quantitative analysis of immunofluorescence analysis by confocal microscopy to track the selective uptake of GeRPs (red) in macrophages (F4/80+, green) in mouse livers at 2

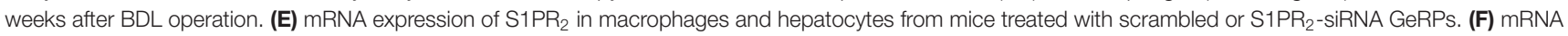
expression of NLRP3, pro-IL-1 $\beta$, and pro-IL-18 in liver tissues from mice treated with scrambled or S1PR2-siRNA GeRPs. (G) ELISA analysis of IL-1 $\beta$ and IL-18 levels in serum. Data are presented as the mean \pm SEM. $n=6$ per group. Student's $t$-test was used in panel (E) and two-way ANOVA was used in panels $(\mathbf{F}, \mathbf{G}) .{ }^{*} p<0.05$ vs. sham group; ${ }^{\#} p<0.05$ vs. BDL-treated alone. 


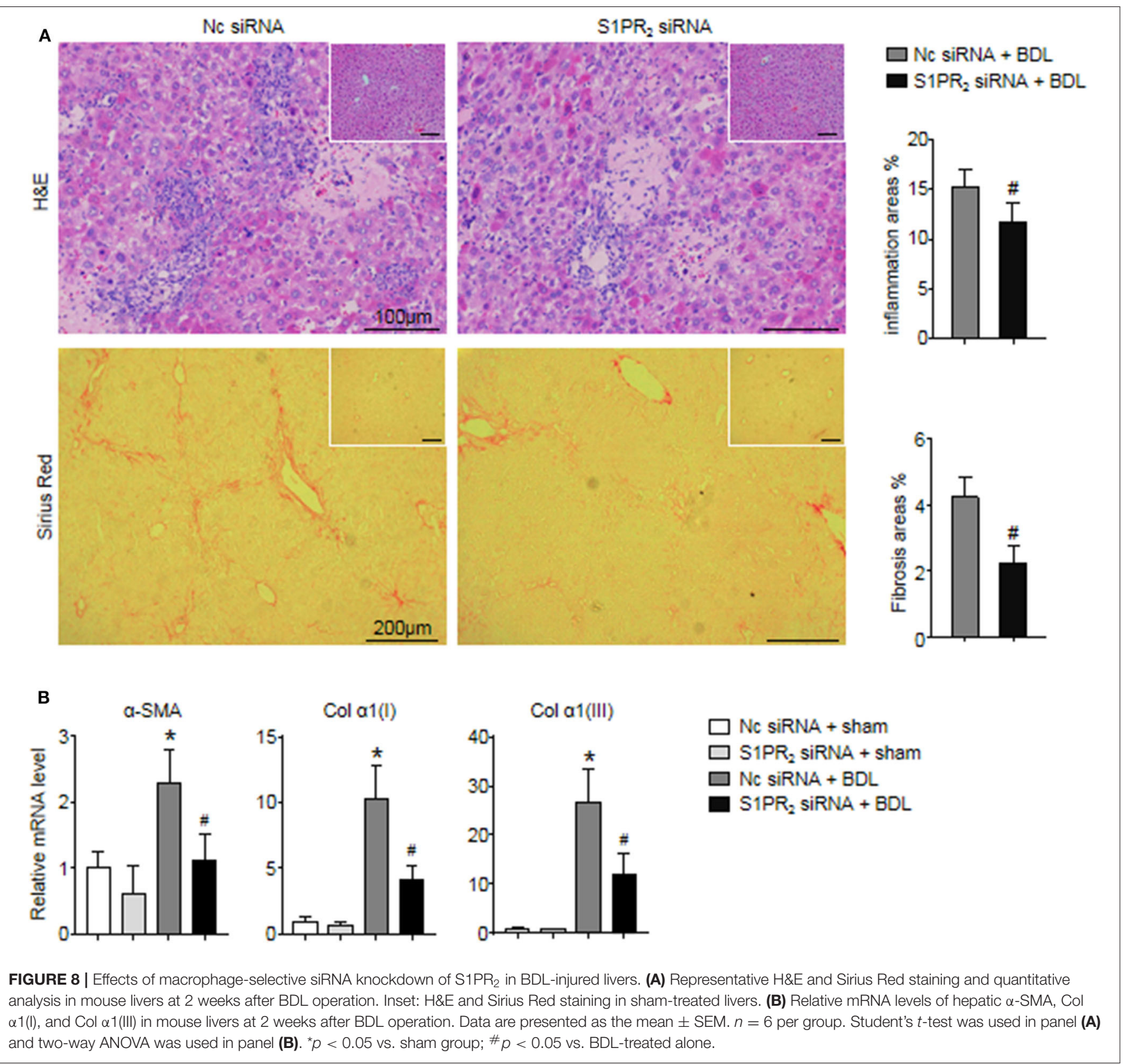

including $\alpha$-smooth muscle actin ( $\alpha$-SMA), procollagen $\alpha 1$ (I) [Col $\alpha 1(\mathrm{I})$ ], procollagen $\alpha 1(\mathrm{III})$ [Col $\alpha 1(\mathrm{III})]$, in BDL-treated livers (Figure 8B). These results validated that treatment with $\mathrm{S}_{1} \mathrm{PR}_{2}$ siRNA-GeRPs attenuated liver inflammation and fibrogenesis in vivo.

\section{DISCUSSION}

Here, our results highlighted the importance of BMMs as key effectors of the NLRP3 function via an overactive S1P/S1PR 2 system and identified the macrophage $\mathrm{S}_{1} \mathrm{PR}_{2}$ as a promising molecular and therapeutic target of cholestatic liver injury. Our work provided several new findings as follows: (1) BMMs were the main origin of $\mathrm{NLRP}^{+}$cells in BDL-injured livers, but not dendritic cells, endothelial cells, T cells, and hepatocytes; (2) S1P induced NLRP3 inflammasome priming and considerable inflammatory cytokine (IL-1 $\beta$ and IL-18) secretion via S1PR in the absence of another stimulus for NLRP3 inflammasome activation; and (3) selective knockdown of macrophage $\mathrm{S}_{1} \mathrm{PR}_{2}$ by $\mathrm{S}_{1} \mathrm{PR}_{2}$ siRNA-GeRPs treatment attenuated liver inflammation and fibrosis via downregulating NLRP3 inflammasome in BDLinjured livers.

The inflammatory effect of NLRP3 inflammasome has been implicated in the development of various chronic liver diseases that lead to fibrosis and cirrhosis (38). Data from several 
publications suggest that NLRP3 can be expressed both in hepatocytes and hepatic non-parenchymal cells, such as Kupffer cells, dendritic cells, sinusoidal endothelial cells, and stellate cells $(5,31,39-41)$. Our current data showed that the majority of $\mathrm{NLRP}^{+}$cells were F4/80 ${ }^{+}$macrophages $(79.5 \pm 6.3 \%)$, whereas only a small fraction of the $\mathrm{NLRP}^{+}$cells were other hepatic non-parenchymal cells, including $\mathrm{T}$ cells, endothelial cells, and dendritic cells. Notably, BMMs contributed to a significant proportion $(92.4 \pm 5.6 \%)$ of $\mathrm{NLRP}^{+}$macrophages in BDLinjured livers, while there was no significant change in the expression of NLRP3 in Kupffer cells, supporting that BMMs played pivotal roles in NLRP3 function. Previous studies have provided evidence that NLRP3 exists and is functionally active in hepatocytes $(40,41)$. In our study, NLRP3 in the livers of BDL-treated mouse colocalize with $\mathrm{EGFP}^{+}$macrophages, but not with hepatocytes. These results supported that BMMs were key effector cells of NLRP3-driven immune responses during cholestatic liver injury.

The inflammatory effect of NLRP3 inflammasome has been implicated in the development of many chronic liver diseases that lead to fibrosis and cirrhosis (38). Here, we demonstrated that S1P specifically induced NLRP3 mRNA expression compared to other inflammasome family members. Although S1P also regulated the expression of AIM2 and NLRC4, the mRNA foldchanges of AIM2 and NLRC4 were much lower than that of NLRP3, implying that S1P is a robust and effective NLRP3 inflammasome inducer. Previous studies show that $\mathrm{S}_{\mathrm{PR}}$, $S 1 \mathrm{PR}_{2}$, and $\mathrm{S} 1 \mathrm{PR}_{3}$ are highly expressed in the liver and that the expression levels of $\mathrm{S}_{1} \mathrm{PR}_{4}$ and $\mathrm{S} 1 \mathrm{PR}_{5}$ are too low to be detected (17). Here, we reported that S1P induced considerable IL- $1 \beta$ and IL-18 secretion via $S 1 \mathrm{PR}_{2}$ in $\mathrm{BMMs}$ in the absence of another stimulus for NLRP3 inflammasome activation. In another report, LPS/S1PR 1 signaling participates in NLRP3 expression and IL-1 $\beta$ production in tumor-associated macrophages (42). The reason for such a discrepancy may come from the use of different stimulants or the heterogeneity of macrophage between tumor-associated macrophages and inflammatory macrophages. Furthermore, some pro-inflammatory cytokines, such as TNF$\alpha$, also stimulate the gene expression of NLRP3 and proIL-1 $\beta$ in macrophages $(43,44)$, whereas S1P might exert a more powerful effect on NLRP3 inflammasome priming than TNF- $\alpha(43,44)$.

S1P/S1PRs signaling has been indicated to regulate immune response in various inflammatory diseases $(10,14,25)$. In this study, we noted that S1P was a powerful pro-inflammatory molecular in both promoting NLRP3 inflammasome priming and activation and regulating M1 phenotype polarization of BMMs. While a previous study has shown that S1P reduces LPS-induced inflammatory gene expression and could regulate the inflammatory phenotype of LPS-stimulated mouse macrophages (45), the reason for such a discrepancy might come from the difference between C57BL/6 mice and ICR mice. Our previous results have documented that BMMs from ICR mice abundantly expressed $S 1 \mathrm{PR}_{1}$, $S 1 \mathrm{PR}_{2}$, and $S 1 \mathrm{PR}_{3}$, whereas Hughes JE et al. found no expression of $\mathrm{S}_{1 \mathrm{PR}_{3}}$ in $\mathrm{BMMs}$ from C57BL/6 mice $(15,45)$. Interestingly, Hughes $\mathrm{JE}$ et al. noted that S1P induced a significant increase of TNF- $\alpha$, and had no effects on Arginase-1 expression, which were similar to our results (45). Further studies will be needed to illustrate the role of S1P/S1PRs signaling in regulating phenotype polarization of BMMs in inflammatory diseases.

In consideration of the importance of S1PRs for the treatment of multiple inflammatory diseases, drugs targeting S1PRs have been developed. Fingolimod, the first S1PRs modulator, has been approved by the United States Food and Drug Administration to treat relapsing multiple sclerosis $(27,46)$. Owing to the ubiquitous and overlapping expression of S1PRs in various kinds of cells, fingolimod treatment can cause undesirable side effects as a result of its interaction with other S1PRs subtypes (27). In addition, S1PRs is also involved in bile acid signaling in the liver. Conjugated bile acids increase nuclear S1P and induce genes encoding enzymes and transporters involved in glucose, lipid, and sterol metabolism in hepatocytes via $\mathrm{S}_{1} \mathrm{PR}_{2}(47,48)$. Thus, the traditional delivery method, systemic administration, can lead to systemic side effects and low bioavailability when high doses are required at a localized area $(28,49)$. Recently, nucleic acid therapeutics, such as sequencespecific gene silencing by siRNA, are also being explored as novel therapeutic strategies for a variety of diseases $(30,49,50)$. Development of a strategy to efficiently deliver pharmacological inhibitors or siRNA into specific cells, such as macrophages, is expected to be a more effective therapy for the treatment of liver diseases $(30,51)$.

In this study, one striking finding was that selective knockdown of the macrophage $S 1 \mathrm{PR}_{2}$ replicated the effect of JTE-013 in remarkable attenuation of NLRP3 inflammasome priming and activation during cholestatic liver injury (data not shown). Increasingly, conjugated bile acids have also been implicated in various inflammatory diseases by activating specific nuclear receptors and $G$ protein-coupled receptors (GPCRs), such as $\mathrm{S}_{\mathrm{PR}}(52,53)$. In a recent study, researchers found that blockage of $\mathrm{S}_{\mathrm{PR}}$ substantially reduced mature IL-1 $\beta$ production and alleviated colonic inflammation induced by conjugated bile acids (53). Our previous studies have documented that a significant proportion $(48.2 \pm 3.5 \%)$ of hepatic non-parenchymal cells are BMMs, supporting the important role of macrophages in BDL-induced liver injury (34). Selective knockdown of macrophage $\mathrm{S}_{\mathrm{PR}} \mathrm{PR}_{2}$ also attenuated the hepatic inflammation and fibrosis in cholestatic liver injury, as compared to scrambled siRNA-treated controls. Consistent with previous reports, only $\mathrm{F} 4 / 80^{+}$macrophages, which have strong phagocytic activity, can effectively internalize GeRPs $(29,30)$. Moreover, GeRPs are undetectable in peripheral blood monocytes, while GeRPs are enriched $\sim 10$-fold in $\mathrm{CD}^{+} 8^{+}$ macrophages compared to $\mathrm{CD}^{+}$lymphocytes $(29,30)$. Thus, the GeRP delivery system is capable of targeting selectivity to macrophages and inducing macrophage-specific gene silence. As NLRP3 mainly expressed and functioned in macrophages via $\mathrm{S} 1 \mathrm{P} / \mathrm{S} 1 \mathrm{PR}_{2}$ signaling, targeting macrophage $\mathrm{S}_{1} \mathrm{PR}_{2}$ with $\mathrm{S}_{1 P R_{2}}$ siRNA-GeRPs was able to effectively inactivate macrophage NLRP3 inflammasome and avoid the potential risks of undesirable side effects. In summary, our results demonstrated that GeRPs-mediated gene silence 
of macrophage $\mathrm{S}_{1} \mathrm{PR}_{2}$ attenuated liver inflammation and fibrogenesis triggered by NLRP3 inflammasome, which provided an example for the treatment of chronic liver injury in the near future.

\section{DATA AVAILABILITY STATEMENT}

The datasets generated for this study are available on request to the corresponding author.

\section{ETHICS STATEMENT}

The animal study was reviewed and approved by the Ethics Committee of Capital Medical University. The study was conducted in accordance with the Declaration of Helsinki, and the protocol was approved by the Ethics Committee of Beijing Shijitan Hospital, Capital Medical University, Beijing, China (Project identification code: 2018EC-1). The patients/participants provided their written informed consent to participate in this study.

\section{REFERENCES}

1. Awad F, Assrawi E, Louvrier C, Jumeau C, Georgin-Lavialle S, Grateau G, et al. Inflammasome biology, molecular pathology and therapeutic implications. Pharmacol Ther. (2018) 187:133-49. doi: 10.1016/j.pharmthera.2018.02.011

2. Mridha AR, Wree A, Robertson AAB, Yeh MM, Johnson CD, Van Rooyen DM, et al. NLRP3 inflammasome blockade reduces liver inflammation and fibrosis in experimental NASH in mice. J Hepatol. (2017) 66:103746. doi: 10.1016/j.jhep.2017.01.022

3. Wree A, McGeough MD, Pena CA, Schlattjan M, Li H, Inzaugarat $\mathrm{ME}$, et al. NLRP3 inflammasome activation is required for fibrosis development in NAFLD. J Mol Med (Berl). (2014) 92:1069-82. doi: 10.1007/s00109-014-1170-1

4. Wree A, Eguchi A, McGeough MD, Pena CA, Johnson CD, Canbay A, et al. NLRP3 inflammasome activation results in hepatocyte pyroptosis, liver inflammation, and fibrosis in mice. Hepatology. (2014) 59:898910. doi: 10.1002/hep.26592

5. Szabo G, Csak T. Inflammasomes in liver diseases. J Hepatol. (2012) 57:64254. doi: 10.1016/j.jhep.2012.03.035

6. He Y, Hara H, Nunez G. Mechanism and regulation of NLRP3 inflammasome activation. Trends Biochem Sci. (2016) 41:101221. doi: 10.1016/j.tibs.2016.09.002

7. Fyrst H, Saba JD. An update on sphingosine-1-phosphate and other sphingolipid mediators. Nat Chem Biol. (2010) 6:48997. doi: $10.1038 /$ nchembio.392

8. Ksiazek M, Chacinska M, Chabowski A, Baranowski M. Sources, metabolism, and regulation of circulating sphingosine-1-phosphate. J Lipid Res. (2015) 56:1271-81. doi: 10.1194/jlr.R059543

9. Takabe K, Paugh SW, Milstien S, Spiegel S. "Inside-out" signaling of sphingosine-1-phosphate: therapeutic targets. Pharmacol Rev. (2008) 60:18195. doi: 10.1124/pr.107.07113

10. Gomez-Munoz A, Presa N, Gomez-Larrauri A, Rivera IG, Trueba M, Ordonez M. Control of inflammatory responses by ceramide, sphingosine 1-phosphate and ceramide 1-phosphate. Prog Lipid Res. (2016) 61:5162. doi: 10.1016/j.plipres.2015.09.002

11. Li C, Zheng S, You H, Liu X, Lin M, Yang L, et al. Sphingosine 1phosphate $(\mathrm{S} 1 \mathrm{P}) / \mathrm{S} 1 \mathrm{P}$ receptors are involved in human liver fibrosis by action on hepatic myofibroblasts motility. J Hepatol. (2011) 54:120513. doi: $10.1016 /$ j.jhep. 2010.08 .028

12. Yang L, Yue S, Yang L, Liu X, Han Z, Zhang Y, et al. Sphingosine kinase/sphingosine 1-phosphate $(\mathrm{S} 1 \mathrm{P}) / \mathrm{S} 1 \mathrm{P}$ receptor axis is

\section{AUTHOR CONTRIBUTIONS}

LL conceived and designed the study. LH designed the research studies, conducted experiments, acquired data, and analyzed data. LH, LeY, NC, and LL drafted the manuscript. XZhao, XZhou, and LinY conducted experiments, acquired data, and provided reagents. CD and FL provided human specimens and collected data. All authors contributed to the article and approved the submitted version.

\section{FUNDING}

This work was supported by grants from the National Natural and Science Foundation of China (81430013, 81970532).

\section{SUPPLEMENTARY MATERIAL}

The Supplementary Material for this article can be found online at: https://www.frontiersin.org/articles/10.3389/fimmu. 2020.01149/full\#supplementary-material

involved in liver fibrosis-associated angiogenesis. J Hepatol. (2013) 59:114-23. doi: 10.1016/j.jhep.2013.02.021

13. Sato M, Ikeda H, Uranbileg B, Kurano M, Saigusa D, Aoki J, et al. Sphingosine kinase-1, S1P transporter spinster homolog 2 and S1P2 mRNA expressions are increased in liver with advanced fibrosis in human. Sci Rep. (2016) 6:32119. doi: 10.1038/srep32119

14. Yang L, Han Z, Tian L, Mai P, Zhang Y, Wang L, et al. Sphingosine 1-phosphate receptor 2 and 3 mediate bone marrow-derived monocyte/macrophage motility in cholestatic liver injury in mice. Sci Rep. (2015) 5:13423. doi: 10.1038/srep13423

15. Yang J, Yang L, Tian L, Ji X, Yang L, Li L. Sphingosine 1-phosphate (S1P)/S1P receptor $2 / 3$ axis promotes inflammatory $\mathrm{M} 1$ polarization of bone marrow-derived monocyte/macrophage via G(alpha)i/o/PI3K/JNK pathway. Cell Physiol Biochem. (2018) 49:1677-93. doi: 10.1159/000493611

16. Yang J, Chang N, Yang L, Ji X, Zhou X, Tian L, et al. Sphingosine 1phosphate receptor blockade affects pro-inflammatory bone marrow-derived macrophages and relieves mouse fatty liver injury. Int J Mol Sci. (2019) 20:4695. doi: 10.3390/ijms20194695

17. Wang Y, Aoki H, Yang J, Peng K, Liu R, Li X, et al. The role of sphingosine 1-phosphate receptor 2 in bile-acid-induced cholangiocyte proliferation and cholestasis-induced liver injury in mice. Hepatology. (2017) 65:200518. doi: 10.1002/hep. 29076

18. Xiao Y, Liu R, Li X, Gurley EC, Hylemon PB, Lu Y, et al. Long noncoding RNA H19 contributes to cholangiocyte proliferation and cholestatic liver fibrosis in biliary atresia. Hepatology. (2019) 70:1658-73. doi: 10.1002/ hep.30698

19. Zhao S, Adebiyi MG, Zhang Y, Couturier JP, Fan X, Zhang H, et al. Sphingosine-1-phosphate receptor 1 mediates elevated IL-6 signaling to promote chronic inflammation and multitissue damage in sickle cell disease. Faseb J. (2018) 32:2855-65. doi: 10.1096/fj.201600788RR

20. Skoura A, Michaud J, Im DS, Thangada S, Xiong Y, Smith JD, et al. Sphingosine-1-phosphate receptor-2 function in myeloid cells regulates vascular inflammation and atherosclerosis. Arterioscler Thromb Vasc Biol. (2011) 31:81-5. doi: 10.1161/ATVBAHA.110.213496

21. Xu W, Lu C, Zhang F, Shao J, Zheng S. Dihydroartemisinin restricts hepatic stellate cell contraction via an FXR-S1PR2-dependent mechanism. IUBMB Life. (2016) 68:376-87. doi: 10.1002/iub.1492

22. Kageyama Y, Ikeda H, Watanabe N, Nagamine M, Kusumoto Y, Yashiro M, et al. Antagonism of sphingosine 1-phosphate receptor 2 causes a selective reduction of portal vein pressure in bile duct-ligated rodents. Hepatology. (2012) 56:1427-38. doi: 10.1002/hep.25780 
23. Wang R, Ding Q, Yaqoob U, de Assuncao TM, Verma VK, Hirsova $\mathrm{P}$, et al. Exosome adherence and internalization by hepatic stellate cells triggers sphingosine 1-phosphate-dependent migration. J Biol Chem. (2015) 290:30684-96. doi: 10.1074/jbc.M115.671735

24. Ikeda H, Watanabe N, Ishii I, Shimosawa T, Kume Y, Tomiya T, et al. Sphingosine 1-phosphate regulates regeneration and fibrosis after liver injury via sphingosine 1-phosphate receptor 2. J Lipid Res. (2009) 50:55664. doi: 10.1194/jlr.M800496-JLR200

25. Bryan AM, Del Poeta. M. Sphingosine-1-phosphate receptors and innate immunity. Cell Microbiol. (2018) 20:e12836. doi: 10.1111/cmi.12836

26. O'Sullivan S, Dev KK. Sphingosine-1-phosphate receptor therapies: advances in clinical trials for CNS-related diseases. Neuropharmacology. (2017) 113(Pt B):597-607. doi: 10.1016/j.neuropharm.2016.11.006

27. Chaudhry BZ, Cohen JA, Conway DS. Sphingosine 1-phosphate receptor modulators for the treatment of multiple sclerosis. Neurotherapeutics. (2017) 14:859-73. doi: 10.1007/s13311-017-0565-4

28. Kunkel GT, Maceyka M, Milstien S, Spiegel S. Targeting the sphingosine-1phosphate axis in cancer, inflammation and beyond. Nat Rev Drug Discov. (2013) 12:688-702. doi: 10.1038/nrd4099

29. Tesz GJ, Aouadi M, Prot M, Nicoloro SM, Boutet E, Amano SU, et al. Glucan particles for selective delivery of siRNA to phagocytic cells in mice. Biochem J. (2011) 436:351-62. doi: 10.1042/BJ20110352

30. Jourdan T, Godlewski G, Cinar R, Bertola A, Szanda G, Liu J, et al. Activation of the Nlrp3 inflammasome in infiltrating macrophages by endocannabinoids mediates beta cell loss in type 2 diabetes. Nat Med. (2013) 19:113240. doi: $10.1038 / \mathrm{nm} .3265$

31. Musso G, Cassader M, Gambino R. Non-alcoholic steatohepatitis: emerging molecular targets and therapeutic strategies. Nat Rev Drug Discov. (2016) 15:249-74. doi: 10.1038/nrd.2015.3

32. Ju C, Tacke F. Hepatic macrophages in homeostasis and liver diseases: from pathogenesis to novel therapeutic strategies. Cell Mol Immunol. (2016) 13:316-27. doi: 10.1038/cmi.2015.104

33. Mai P, Yang L, Tian L, Wang L, Jia S, Zhang Y, et al. Endocannabinoid system contributes to liver injury and inflammation by activation of bone marrowderived monocytes/macrophages in a CB1-dependent manner. J Immunol. (2015) 195:3390-401. doi: 10.4049/jimmunol.1403205

34. Han Z, Zhu T, Liu X, Li C, Yue S, Liu X, et al. 15-deoxy-Delta12,14 -prostaglandin J2 reduces recruitment of bone marrow-derived monocyte/macrophages in chronic liver injury in mice. Hepatology. (2012) 56:350-60. doi: 10.1002/hep. 25672

35. Lacey DC, Achuthan A, Fleetwood AJ, Dinh H, Roiniotis J, Scholz GM, et al. Defining GM-CSF- and macrophage-CSF-dependent macrophage responses by in vitro models. J Immunol. (2012) 188:5752-65. doi: 10.4049/jimmunol.1103426

36. Kurano M, Ikeda H, Iso ON, Hara M, Tsukamoto K, Yatomi Y. Regulation of the metabolism of apolipoprotein $\mathrm{M}$ and sphingosine 1-phosphate by hepatic PPAR $\gamma$ activity. Biochem J. (2018) 475:2009-24. doi: 10.1042/BCJ20 180052

37. Coll RC, Robertson AA, Chae JJ, Higgins SC, Munoz-Planillo R, Inserra $\mathrm{MC}$, et al. A small-molecule inhibitor of the NLRP3 inflammasome for the treatment of inflammatory diseases. Nat Med. (2015) 21:24855. doi: $10.1038 / \mathrm{nm} .3806$

38. Tilg H, Moschen AR, Szabo G. Interleukin-1 and inflammasomes in alcoholic liver disease/acute alcoholic hepatitis and nonalcoholic fatty liver disease/nonalcoholic steatohepatitis. Hepatology. (2016) 64:955-65. doi: 10.1002/hep.28456

39. Yu X, Lan P, Hou X, Han Q, Lu N, Li T, et al. HBV inhibits LPSinduced NLRP3 inflammasome activation and IL-1beta production via suppressing the NF- $\kappa \mathrm{B}$ pathway and ROS production. J Hepatol. (2017) 66:693-702. doi: 10.1016/j.jhep.2016.12.018

40. Lu Y, Xu S, Chen H, He M, Deng Y, Cao Z, et al. CdSe/ZnS quantum dots induce hepatocyte pyroptosis and liver inflammation via NLRP3 inflammasome activation. Biomaterials.

(2016) 90:27-39. doi: 10.1016/j.biomaterials.2016.03.003

41. Han CY, Rho HS, Kim A, Kim TH, Jang K, Jun DW, et al. FXR inhibits endoplasmic reticulum stress-induced NLRP3 inflammasome in hepatocytes and ameliorates liver injury. Cell Rep. (2018) 24:298599. doi: 10.1016/j.celrep.2018.07.068

42. Weichand B, Popp R, Dziumbla S, Mora J, Strack E, Elwakeel $\mathrm{E}$, et al. S1PR1 on tumor-associated macrophages promotes lymphangiogenesis and metastasis via NLRP3/IL-1ß. J Exp Med. (2017) 214:2695-713. doi: 10.1084/jem.20160392

43. Jamsen E, Pajarinen J, Kouri VP, Rahikkala A, Goodman SB, Manninen $\mathrm{M}$, et al. Tumor necrosis factor primes and metal particles activate the NLRP3 inflammasome in human primary macrophages. Acta Biomater. (2020) 108:347-357. doi: 10.1016/j.actbio.2020.03.017

44. McGeough MD, Wree A, Inzaugarat ME, Haimovich A, Johnson CD, Pena CA, et al. TNF regulates transcription of NLRP3 inflammasome components and inflammatory molecules in cryopyrinopathies. J Clin Invest. (2017) 127:4488-97. doi: 10.1172/JCI90699

45. Hughes JE, Srinivasan S, Lynch KR, Proia RL, Ferdek P, Hedrick CC. Sphingosine-1-phosphate induces an antiinflammatory phenotype in macrophages. Circ Res. (2008) 102:9508. doi: 10.1161/CIRCRESAHA.107.170779

46. Peyrin-Biroulet L, Christopher R, Behan D, Lassen C. Modulation of sphingosine-1-phosphate in inflammatory bowel disease. Autoimmun Rev. (2017) 16:495-503. doi: 10.1016/j.autrev.2017.03.007

47. Nagahashi M, Takabe K, Liu R, Peng K, Wang X, Wang Y, et al. Conjugated bile acid-activated S1P receptor 2 is a key regulator of sphingosine kinase 2 and hepatic gene expression. Hepatology. (2015) 61:1216-26. doi: 10.1002/hep.27592

48. Cao R, Cronk ZX, Zha W, Sun L, Wang X, Fang Y, et al. Bile acids regulate hepatic gluconeogenic genes and farnesoid $X$ receptor via $G(a l p h a) i-$ protein-coupled receptors and the AKT pathway. J Lipid Res. (2010) 51:223444. doi: 10.1194/jlr.M004929

49. Wittrup A, Lieberman J. Knocking down disease: a progress report on siRNA therapeutics. Nat Rev Genet. (2015) 16:543-52. doi: 10.1038/nrg3978

50. Bangen JM, Hammerich L, Sonntag R, Baues M, Haas U, Lambertz $\mathrm{D}$, et al. Targeting CCl4 -induced liver fibrosis by RNA interferencemediated inhibition of cyclin E1 in mice. Hepatology. (2017) 66:124257. doi: 10.1002/hep. 29275

51. Xu C, Lu Z, Luo Y, Liu Y, Cao Z, Shen S, et al. Targeting of NLRP3 inflammasome with gene editing for the amelioration of inflammatory diseases. Nat Commun. (2018) 9:4092. doi: 10.1038/s41467-018-06522-5

52. McMillin M, Frampton G, Grant S, Khan S, Diocares J, Petrescu A, et al. Bile acid-mediated sphingosine-1-phosphate receptor 2 signaling promotes neuroinflammation during hepatic encephalopathy in mice. Front Cell Neurosci. (2017) 11:191. doi: 10.3389/fncel.2017.00191

53. Zhao S, Gong Z, Du X, Tian C, Wang L, Zhou J, et al. Deoxycholic acidmediated sphingosine-1-phosphate receptor 2 signaling exacerbates DSSinduced colitis through promoting cathepsin B release. J Immunol Res. (2018) 2018:2481418. doi: 10.1155/2018/2481418

Conflict of Interest: The authors declare that the research was conducted in the absence of any commercial or financial relationships that could be construed as a potential conflict of interest.

Copyright (C) 2020 Hou, Yang, Chang, Zhao, Zhou, Dong, Liu, Yang and Li. This is an open-access article distributed under the terms of the Creative Commons Attribution License (CC BY). The use, distribution or reproduction in other forums is permitted, provided the original author(s) and the copyright owner(s) are credited and that the original publication in this journal is cited, in accordance with accepted academic practice. No use, distribution or reproduction is permitted which does not comply with these terms. 